\title{
Flexible Models for Solar Sail Control
}

\author{
Suzanne Weaver Smith ${ }^{*}$, Haiping Song ${ }^{\dagger}$, John R. Baker ${ }^{\ddagger}$ and Jonathan Black ${ }^{\S}$ \\ University of Kentucky, Lexington, KY, 40506 \\ and \\ Danniella M. Muheim ${ }^{* *}$ \\ NASA Langley Research Center, Hampton, VA, 23681-2199
}

\begin{abstract}
Solar sails employ a unique form of propulsion, gaining momentum from incident and reflected photons. However, the momentum transferred by an individual photon is extremely small. Consequently, a solar sail must have an extremely large surface area and also be extremely light. The flexibility of the sail then must be considered when designing or evaluating control laws. In this paper, solar sail flexibility and its influence on control effectiveness is considered using idealized two-dimensional models to represent physical phenomena rather than a specific design. Differential equations of motion are derived for a distributed parameter model of a flexible solar sail idealized as a rotating central hub with two opposing flexible booms. This idealization is appropriate for solar sail designs in which the vibrational modes of the sail and supporting booms move together allowing the sail mass to be distributed along the booms in the idealized model. A reduced analytical model of the flexible response is considered. Linear feedback torque control is applied at the central hub. Two translational disturbances and a torque disturbance also act at the central hub representing the equivalent effect of deflecting sail shape about a reference line. Transient simulations explore different control designs and their effectiveness for controlling orientation, for reducing flexible motion and for disturbance rejection. A second model also is developed as a two-dimensional "pathfinder" model to calculate the effect of solar sail shape on the resultant thrust, in-plane force and torque at the hub. The analysis is then extended to larger models using the finite element method. The finite element modeling approach is verified by comparing results from a two-dimensional finite element model with those from the analytical model. The utility of the finite element modeling approach for this application is then illustrated through examples based on a full finite element model.
\end{abstract}

\section{Introduction}

The advent of solar sail spacecraft has brought with it challenges in the areas of materials and manufacturing, in the areas of modeling and computation and in the areas of design and control. Much progress has been made during the last few years toward completing the vision of solar sail development [1]. Two primary design concepts have emerged for a square solar sail supported by four booms radiating from a central hub $[2,3]$. These concepts differ in the details of sail attachment to the booms, in the design of the booms themselves and in their approach to attitude control. One design includes four scalloped-edge sails with multi-point attachments along telescoping booms constructed of inflatable isogrid sections. Angular positioning of the sail is accomplished via adjustable vanes at the tips of the booms that can be oriented to use the solar pressure to change the solar sail orientation [2]. The other design includes sails that are attached to uniform booms at only five locations: the hub and the four boom tips. The sails include shear compliant borders to reduce wrinkling [4]. This concept includes a fifth boom and tip mass

\footnotetext{
* Donald and Gertrude Lester Professor of Mechanical Engineering, Dept. of Mechanical Engineering, 151 R.G. Anderson Bldg., Assoc. Fellow AIAA.

${ }^{\dagger}$ Research Associate, Dept. of Mechanical Engineering, 151 R.G. Anderson Bldg.

* Assistant Professor, Dept. of Mechanical Engineering, 151 R.G. Anderson Bldg.

${ }^{\S}$ Graduate Research Assistant, Dept. of Mechanical Engineering, 151 R.G. Anderson Bldg., Member AIAA.

** Aerospace Engineer, Computational Structures and Materials Branch, MS 155, Senior Member AIAA.
} 
extending from the central hub out-of-plane with respect to the sail that can be moved to provide attitude control [3]. Control simulations with a rigid sail implemented both of these control concepts and established the feasibility of these approaches $[5,6,7]$. Recently, the static shape and the dynamic response of a generic sail design similar to both concepts have been studied using high-fidelity models and nonlinear finite element (FE) simulations. The effect of variation of design parameters on the dynamic response was also considered for both five-point and multi-point connection sails [8].

The objective of this effort was to develop an initial analytical model to use to consider the impact of flexibility on solar sail attitude control and on sail vibration suppression. Ultimately, this question is studied with nonlinear transient simulations implementing control strategies on reduced versions of high-fidelity models after the simulation methods are verified. The motivational example of a flexible square solar sail design with four booms and results from a high-fidelity ABAQUS FE model are given in section II. To enable rapid development of control models, a two-dimensional simplified analytical model with only two opposite booms of the four is developed in section III. Motion is restricted to one plane. Single-axis torque control is applied to the central hub for vibration suppression and attitude control. The distributed parameter equations of motion for this simplified model for firstmode motion are derived in section IV. In this paper, several studies are performed with the 2-D simplified model whose results are given in section V. First, the effect of disturbance torques with and without linear control feedback for harmonic torque distributions that represent sail wrinkling is studied. Second, the controlled response for different angular initial conditions is studied. Third, studies are performed to examine the influence of the wrinkling disturbance throughout the simulation under no control, delayed control initiation conditions, different feedback control schemes, alternate control laws and different angular initial conditions. A solar disturbance model is developed and used as input for the 2-D simplified model in section VI, where the solar disturbance model determines an equivalent disturbance at the hub attributable to sail shape under solar pressure. Finally, an ANSYS FE model is developed in section VII based on the high-fidelity flexible square solar sail FE model of section II. Control simulations with the ANSYS FE model are demonstrated in section VIII for unit and random force out-ofplane inputs. The simplified analytical model also serves as a verification example for the reduced nonlinear transient FE simulations. A summary and directions of continuing work conclude the paper.

\section{Flexible Square Solar Sail}

The analytical model developed for this effort is a simplified representation of a flexible square solar sail. Design parameter studies were available in which the variations of the lower modes of a uniform-boom five-point connected solar sail were determined for changing design parameters [8]. The effective bending stiffness (EI) of each sail boom varied from $\mathrm{EI}=37.2 \times 10^{3}$ to $382 \times 10^{3} \mathrm{Nm}^{2}$ as the boom thickness was increased from $4.0 \mu \mathrm{m}$ to $41 \mu \mathrm{m}$. Additional information from the parametric study is given within Ref. [8,9]. The first five sail frequencies as a function of increasing boom thickness are plotted in Figure 1a), which is a repeat of Figure 15 of Ref. [8]. The first sail frequency as a function of the boom thickness are plotted in Figure 1b) for both the five-point and multi-point connected sail [9]. For both designs, the shape of the vibration mode associated with the lowest frequency is in the shape of a "drum" mode. A drum mode has its maximum deflection at the outer edge of each triangular sail region, and the booms move in the same direction as (in phase with) the sail. In essence, the sail and boom motions coincide for the first mode. For stiffer booms, the vibration modes associated with the sail membrane become independent of the support boom modes. As the development of solar sails continues, it is anticipated that boom stiffness will be further reduced, and that the dynamics of these sails will be dominated by combined sail-boom modes and even boom-only modes. This observation justifies the study of a reduced flexible solar sail model consisting of uniform booms from a central hub with equivalent masses along the boom length to represent the sails. Although not studied herein, a non-uniform mass distribution could be considered. 

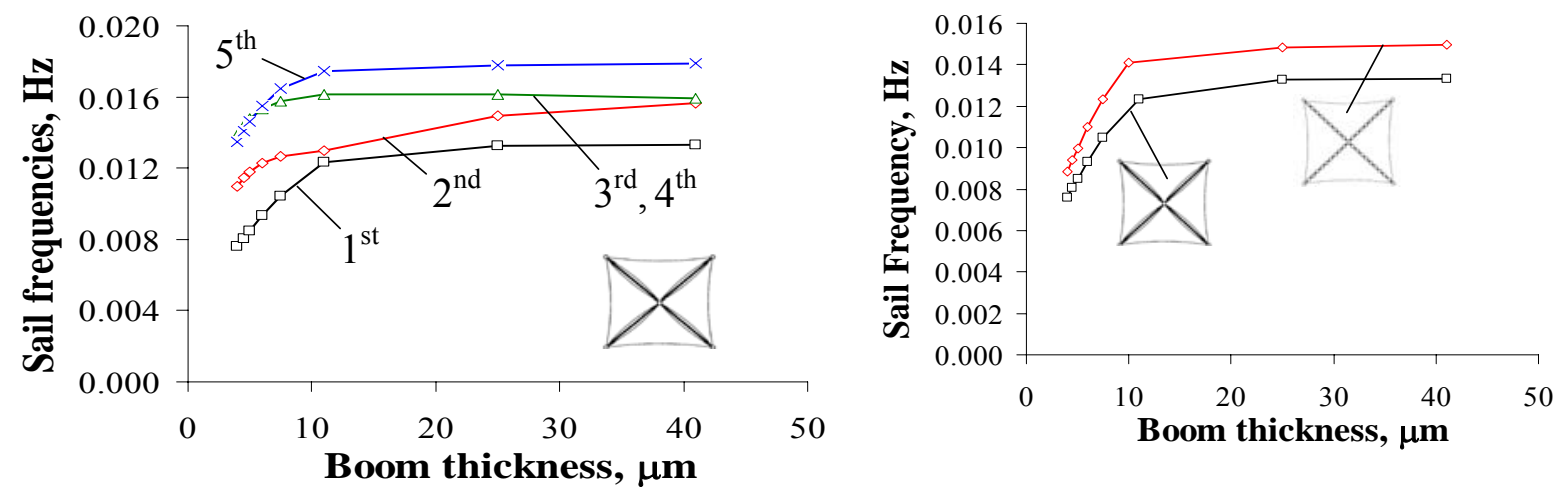

Figure 1. a) Sail mode frequency versus boom thickness for a five-point-connected design b) First frequency variation for a five- and multi-point connected sail designs versus boom thickness

\section{A Two-Dimensional Analytical Model}

The two-dimensional analytical model is a structure consisting of two opposing cantilevered flexible beams connected to a hub. The model includes a central hub mass and two tip masses that are much smaller than the hub mass. Figure 2 is a schematic of the model with coordinate definitions. This structure is subject to axial (beam longitudinal) and transverse (out-of-plane with respect to the solar sail) accelerations, $\ddot{u}_{0}$ and $\ddot{v}_{0}$, respectively. A control torque, $T_{c}$, and a disturbance torque, $T_{d}$, act on the central mass. The mass and rotary inertia of the central hub are $M_{0}$ and $I_{0}$, respectively, while $M_{1}$ and $M_{2}$ are the two masses at the tips of two beams. The mass distribution, Young's modulus, and bending stiffness of each beam are denoted $m_{i}, E_{i}$ and $J_{i}$, respectively, with the beam index $i=1,2$. The hub inertial rotation is $\theta$. The axial and transverse displacement functions for the two beams are respectively $u_{i}\left(s_{i}, t\right)$ and $v_{i}\left(s_{i}, t\right)$ in which $s_{i}$ is the axial coordinate for beam $i$ and $t$ is the time.

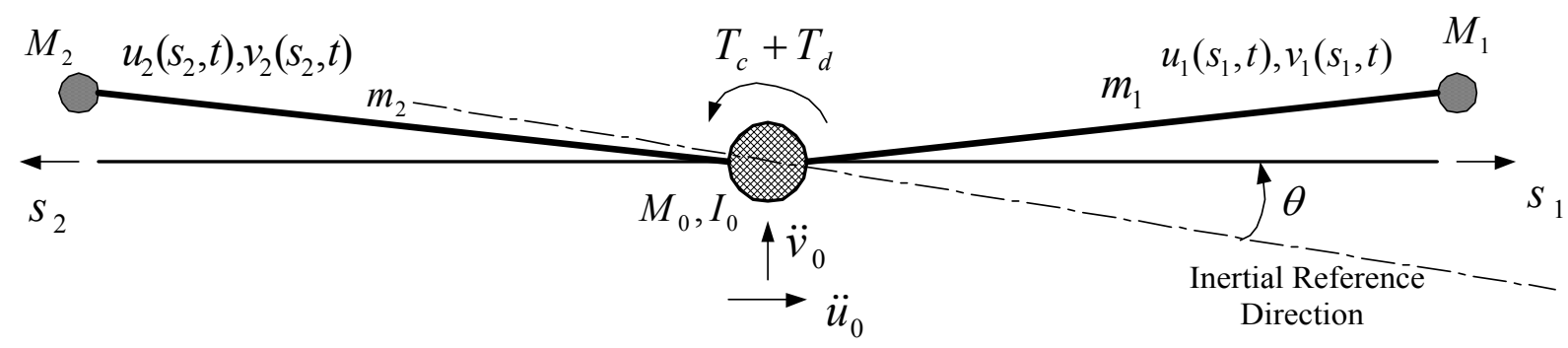

Figure 2. Schematic of a rigid hub with two flexible beams with end masses including modeling parameters and coordinate definitions

Equations of motion for the flexible 2-D model are developed following examples of a rotating flexible-beam satellite in Reference 10 and of multiple-beam flexible solar array support structure in References 11 and 12. Standard assumptions are adopted, including the following:

- the beams are inextensional along the neutral axis,

- the beams have no shear deformation and warping,

- the beams are subject to only axial displacement $u_{i}$ and transverse displacement $v_{i}$,

- damping is viscous, having the coefficient $c_{i}$, and

- gravitational potential energy is negligible.

From the above assumptions, the axial and transverse displacements are related: 


$$
\begin{array}{rr}
\left(1+u_{i}^{\prime}\right)^{2}+v_{i}^{\prime 2}=1 & (i=1,2) \\
\tan \psi_{i}=\frac{v_{i}^{\prime}}{1+u_{i}^{\prime}} & (i=1,2)
\end{array}
$$

where $\psi_{i}$ is the bending angle. Third-order Taylor's expansions for $u_{i}$ and $\psi_{i}$ from (1) and (2) are respectively

$$
\begin{array}{rr}
u_{i}^{\prime} \approx-\frac{1}{2} v_{i}^{\prime 2} & (i=1,2) \\
\psi_{i} \approx v_{i}^{\prime}\left(1+v_{i}^{\prime 2} / 6\right) & (i=1,2)
\end{array}
$$

The transverse motion is out-of-plane with respect to the solar sail if we consider this model to represent an edge-on view. Following Galerkin's approach, the motion can be expanded in terms of modes of the underlying linear model. Typically, a high-fidelity FE simulation is run for a specific excitation to direct the selection of modes for the reduced analytical model. Single mode response can be assumed using the fundamental mode or a higher mode, while multiple modes can be assumed to examine nonlinear modal interactions.

A single-mode model was considered here, based on the first cantilevered bending mode of the boom as shown in Figure 3. In addition, the asymmetric, rather than the symmetric, combination of the boom first modes is assumed. This is physically consistent with the response expected as a result of an applied torque at the hub. Therefore, the transverse (out-of-plane) displacement of the two booms can be expressed in terms of their first bending mode as

$$
v_{i}\left(s_{i}, t\right)=\Phi_{1 i}\left(s_{i}\right) V_{1}(t) \quad(i=1) \quad \text { and } \quad v_{i}\left(s_{i}, t\right)=-\Phi_{1 i}\left(s_{i}\right) V_{1}(t) \quad(i=2)
$$

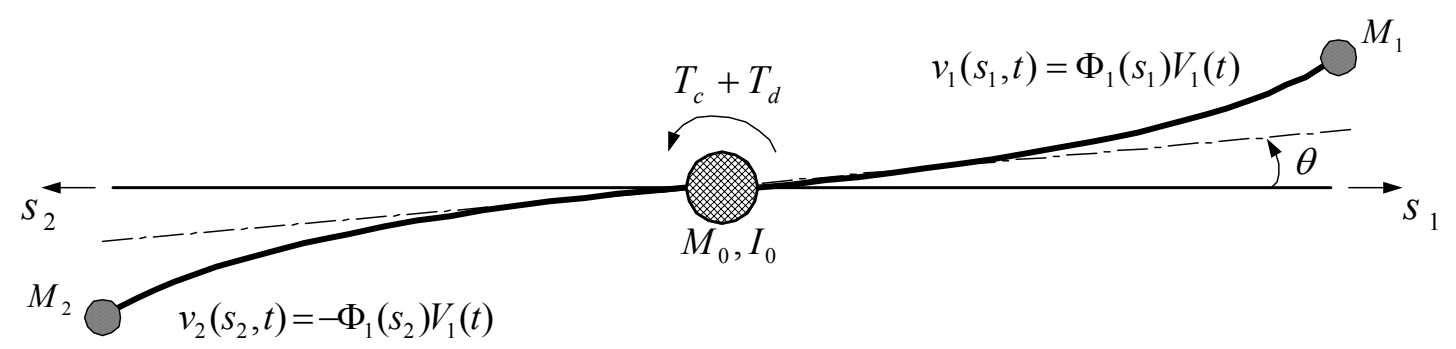

Figure 3. Displacement response actuated by the torque

\section{Derivation of Equations of Motion via Energy Expressions and Hamilton's Principle}

The kinetic energy for the model is

$$
\begin{aligned}
& 2 T=I_{0} \dot{\theta}^{2}+M_{0} \dot{u}_{0}^{2}+M_{0} \dot{v}_{0}^{2}+\int_{0}^{L_{1}} m_{1}\left[\left(\dot{u}_{1}+\dot{u}_{0}\right)^{2}+\left(\dot{v}_{0}+\dot{v}_{1}+s_{1} \dot{\theta}\right)^{2}\right] d s_{1}+M_{1}\left[\dot{u}_{1}\left(L_{1}, t\right)+\dot{u}_{0}\right]^{2} \\
& +M_{1}\left[\dot{v}_{0}+\dot{v}_{1}\left(L_{1}, t\right)+L_{1} \dot{\theta}\right]^{2}+\int_{0}^{L_{2}} m_{2}\left[\left(\dot{u}_{2}-\dot{u}_{0}\right)^{2}+\left(\dot{v}_{0}+\dot{v}_{2}-s_{2} \dot{\theta}\right)^{2}\right] d s_{2} \\
& +M_{2}\left[\dot{u}_{2}\left(L_{2}, t\right)-\dot{u}_{0}\right]^{2}+M_{2}\left[\dot{v}_{0}+\dot{v}_{2}\left(L_{2}, t\right)-L_{2} \dot{\theta}\right]^{2}
\end{aligned}
$$

Using Equations 3 and 4 and expanding the kinetic energy in terms of the first mode using Equation 5, the kinetic energy is now written as

$$
T=a_{0}\left(\dot{u}_{0}^{2}+\dot{v}_{0}^{2}\right)+a_{1} \dot{\theta}^{2}+a_{2} \dot{V}_{1}^{2}+a_{3} \dot{V}_{1} \dot{v}_{0}+a_{4} \dot{\theta}_{0}+a_{5} \dot{V}_{1} \dot{\theta}+a_{6} V_{1} \dot{V}_{1} \dot{u}_{0}+a_{7} V_{1}^{2} \dot{V}_{1}^{2}
$$


where

$$
\begin{aligned}
& a_{0}=\frac{1}{2}\left(M_{0}+m_{1} L_{1}+M_{1}+m_{2} L_{2}+M_{2}\right) \\
& a_{1}=\frac{1}{2}\left(\frac{m_{1} L_{1}^{3}}{3}+M_{1} L_{1}^{2}+\frac{m_{2} L_{2}^{3}}{3}+M_{2} L_{2}^{2}+I_{0}\right) \\
& a_{2}=\frac{1}{2}\left[m_{1} \int_{0}^{L_{1}} \Phi_{11}^{2}\left(s_{1}\right) d s_{1}+M_{1} \Phi_{11}^{2}\left(L_{1}\right)+m_{2} \int_{0}^{L_{2}} \Phi_{12}^{2}\left(s_{2}\right) d s_{2}+M_{2} \Phi_{12}^{2}\left(L_{2}\right)\right] \\
& a_{3}=m_{1} \int_{0}^{L_{1}} \Phi_{11}\left(s_{1}\right) d s_{1}+M_{1} \Phi_{11}\left(L_{1}\right)+m_{2} \int_{0}^{L_{2}} \Phi_{12}\left(s_{2}\right) d s_{2}+M_{2} \Phi_{12}\left(L_{2}\right) \\
& a_{4}=\frac{1}{2}\left(m_{1} L_{1}^{2}+2 M_{1} L_{1}-m_{2} L_{2}^{2}-2 M_{2} L_{2}\right) \\
& a_{5}=m_{1} \int_{0}^{L_{1}} s_{1} \Phi_{11}\left(s_{1}\right) d s_{1}+M_{1} L_{1} \Phi_{11}\left(L_{1}\right)-m_{2} \int_{0}^{L_{2}} s_{2} \Phi_{12}\left(s_{2}\right) d s_{2}-M_{2} L_{2} \Phi_{12}\left(L_{2}\right) \\
& a_{6}=-m_{1} \int_{0}^{L_{1}}\left(\int_{0}^{s_{1}} \Phi_{11}^{\prime 2}(s) d s\right) d s_{1}-M_{1} \int_{0}^{L_{1}} \Phi_{11}^{\prime 2}\left(s_{1}\right) d s_{1}+m_{2} \int_{0}^{L_{2}}\left(\int_{0}^{s_{2}} \Phi_{12}^{\prime 2}(s) d s\right) d s_{2}+M_{2} \int_{0}^{L_{2}} \Phi_{12}^{\prime 2}\left(s_{2}\right) d s_{2} \\
& a_{7}=\frac{1}{2}\left[m_{1}^{2} \int_{0}^{L_{1}}\left(\int_{0}^{s_{1}} \Phi_{11}^{\prime 2}(s) d s\right)^{2} d s_{1}+M_{1}\left(\int_{0}^{L_{1}} \Phi_{11}^{\prime 2}\left(s_{1}\right) d s_{1}\right)^{L_{2}}+m_{2} \int_{0}^{L_{2}}\left(\int_{0}^{s_{2}} \Phi_{12}^{\prime 2}(s) d s\right)_{0}^{2} d s_{2}+M_{2}\left(\int_{0}^{L_{2}} \Phi_{12}^{\prime 2}\left(s_{2}\right) d s_{2}\right)^{2}\right] .
\end{aligned}
$$

Similarly, the potential energy is

$$
\begin{gathered}
2 V=\int_{0}^{L_{1}} E_{1} J_{1}\left(\psi_{1}^{\prime}\right)^{2} d s_{1}+\int_{0}^{L_{2}} E_{2} J_{2}\left(\psi_{2}^{\prime}\right)^{2} d s_{2} \approx \int_{0}^{L_{1}} E_{1} J_{1}\left(v_{1}^{\prime \prime}\right)^{2}\left[1+\left(v_{1}^{\prime}\right)^{2}\right] d s_{1}+\int_{0}^{L_{2}} E_{2} J_{2}\left(v_{2}^{\prime \prime}\right)^{2}\left[1+\left(v_{2}^{\prime}\right)^{2}\right] d s_{2} \\
=E_{1} J_{1} \int_{0}^{L_{1}} \Phi_{11}^{\prime \prime}{ }^{2}\left(s_{1}\right) V_{1}^{2}\left[1+\Phi_{11}^{\prime}{ }^{2}\left(s_{1}\right) V_{1}^{2}\right] d s_{1}+E_{2} J_{2} \int_{0}^{L_{2}} \Phi_{12}^{\prime \prime}{ }^{2}\left(s_{2}\right) V_{1}^{2}\left[1+\Phi_{12}^{\prime}{ }^{2}\left(s_{2}\right) V_{1}^{2}\right] d s_{2} \\
V=b_{1} V_{1}^{2}+b_{2} V_{1}^{4}
\end{gathered}
$$

where

$$
\begin{aligned}
& b_{1}=\frac{1}{2} E_{1} J_{1} \int_{0}^{L_{1}} \Phi_{11}^{\prime \prime}{ }^{2}\left(s_{1}\right) d s_{1}+\frac{1}{2} E_{2} J_{2} \int_{0}^{L_{2}} \Phi_{12}^{\prime \prime}{ }^{2}\left(s_{2}\right) d s_{2} \\
& b_{2}=\frac{1}{2} E_{1} J_{1} \int_{0}^{L_{1}} \Phi_{11}^{\prime \prime}\left(s_{1}\right) \Phi_{11}^{\prime}\left(s_{1}\right) d s_{1}+\frac{1}{2} E_{2} J_{2} \int_{0}^{L_{2}} \Phi_{12}^{\prime \prime}\left(s_{2}\right) \Phi_{12}^{\prime}\left(s_{2}\right) d s_{2}
\end{aligned}
$$


According to the extended form of the Hamilton's principle,

$$
\begin{aligned}
& \delta I=\delta \int_{t_{1}}^{t_{2}}(T-V) d t+\delta \sum_{i=1}^{2} \int_{t_{1}}^{t_{2}} \int_{0}^{L_{i}} \frac{1}{2} \lambda_{i}\left[1-\left(1+u_{i}^{\prime}\right)^{2}-v_{i}^{\prime 2}\right] d s_{i} d t+ \\
& \int_{t_{1}}^{t_{2}} \delta W_{B} d t+\sum_{i=1}^{2} \int_{t_{1}}^{t_{2}}\left[\int_{0}^{L_{i}}\left(Q_{u_{i}} \delta u_{i}+Q_{v_{i}} \delta v_{i}\right) d s_{i}\right] d t=0
\end{aligned}
$$

where $\delta$ denotes virtual quantities and $\lambda_{i}$ are Lagrange multipliers. $\delta W_{B}$ is the virtual work associated with motion of all the boundaries, and where $\delta W_{B}=\left(T_{c}+T_{d}\right) \delta \theta$ in this model. $Q_{u_{i}}, Q_{v_{i}}$ are the generalized forces associated with the virtual displacements $\delta u_{i}, \delta v_{i}$, where $Q_{u_{i}}=0$, and $Q_{v_{i}}=-C_{i} \dot{v}_{i}$, with $C_{i}$ denoting the damping coefficients.

Inserting Equations 7 and 9 into Equation 10 and considering the virtual work and Lagrange multipliers, two nonlinear, coupled equations of motion are obtained:

$$
\left\{\begin{array}{l}
2 a_{1} \ddot{\theta}+a_{5} \ddot{V}_{1}=\left(T_{c}+T_{d}\right)-a_{4} \ddot{v}_{0} \\
a_{5} \ddot{\theta}+2 a_{2} \ddot{V}_{1}+c_{0} \dot{V}_{1}+2 b_{1} V_{1}=\left(d_{0}-4 b_{2}\right) V_{1}^{3}-a_{6} \ddot{u}_{0} V_{1}-2 a_{7}\left(V_{1} \dot{V}_{1}^{2}+V_{1}^{2} \ddot{V}_{1}\right)-a_{3} \ddot{v}_{0}
\end{array}\right.
$$

where

$$
\begin{aligned}
& c_{0}=\int_{0}^{L_{1}} c_{1} \Phi_{11}^{2}\left(s_{1}\right) d s_{1}+\int_{0}^{L_{2}} c_{2} \Phi_{12}^{2}\left(s_{2}\right) d s_{2} \\
& d_{0}=-\frac{1}{2}\left[\int_{0}^{L_{1}} \lambda_{1} \Phi_{11}^{4}\left(s_{1}\right) d s_{1}+\int_{0}^{L_{2}} \lambda_{2} \Phi_{12}^{4}\left(s_{2}\right) d s_{2}\right]
\end{aligned}
$$

Equation 11a can be used to solve for the angular acceleration,

$$
\ddot{\theta}=\frac{T_{c}}{2 a_{1}}-\frac{a_{5}}{2 a_{1}} \ddot{V}_{1}-\frac{a_{4}}{2 a_{1}} \ddot{v}_{0}
$$

and inserted into Equation $11 \mathrm{~b}$ to yield the nonlinear dynamic equation of motion for the vibration response of the idealized sail model

$$
\ddot{V}_{1}+A_{1} \dot{V}_{1}+\left(A_{2}-A_{3} \ddot{u}_{0}\right) V_{1}=A_{4} V_{1}^{3}+A_{5} V_{1} \dot{V}_{1}^{2}+A_{5} V_{1}^{2} \ddot{V}_{1}+A_{6} \ddot{v}_{0}+A_{7}\left(T_{c}+T_{d}\right)
$$

in which

$$
\begin{aligned}
& A_{1}=\frac{2 a_{1} c_{0}}{4 a_{1} a_{2}-a_{5}^{2}} ; A_{2}=\frac{4 a_{1} b_{1}}{4 a_{1} a_{2}-a_{5}^{2}} ; A_{3}=-\frac{2 a_{1} a_{6}}{4 a_{1} a_{2}-a_{5}^{2}} ; A_{4}=\frac{2 a_{1}\left(d_{0}-4 b_{2}\right)}{4 a_{1} a_{2}-a_{5}^{2}} ; A_{5}=-\frac{4 a_{1} a_{7}}{4 a_{1} a_{2}-a_{5}^{2}} ; \\
& A_{6}=\frac{a_{4} a_{5}-2 a_{1} a_{3}}{4 a_{1} a_{2}-a_{5}^{2}} ; A_{7}=-\frac{a_{5}}{4 a_{1} a_{2}-a_{5}^{2}} .
\end{aligned}
$$

Note that expansion of the motion in terms of the symmetric combination of the first boom modes yields zero coefficients for $A_{3}$ and $A_{7}$, rendering the motion uncontrollable with the resultant control torque $T_{c}$ at the central hub. 


\section{Disturbance Control and Angular Position Control Using $T_{c}$}

Based on the nonlinear dynamic equation of motion (Equation 13), two state variables are defined: $x_{1}=V_{1}$ and $\quad x_{2}=\dot{V}_{1}$. First-order state control equations are then written as

$$
\left\{\begin{array}{l}
\dot{x}_{1}=x_{2} \\
\dot{x}_{2}=\frac{1}{1-A_{5} x_{1}^{2}}\left(A_{3} \ddot{u}_{0} x_{1}+A_{4} x_{1}^{3}+A_{5} x_{1} x_{2}^{2}+A_{6} \ddot{v}_{0}+A_{7} T_{c}+A_{7} T_{d}-A_{1} x_{2}-A_{2} x_{1}\right) \\
T_{c}=K_{p} x_{1}+K_{d} x_{2}
\end{array}\right.
$$

The disturbances acting on the hub are $T_{d}, \ddot{u}_{0}, \ddot{v}_{0}$. These disturbances are the resultants at the hub for excitations outside the mission profile.

A control torque based on the vibrational response states is

$$
T_{c}=K_{p} x_{1}+K_{d} x_{2} \quad t \geq t_{1}
$$

in which $K_{p}$ and $K_{d}$ are respectively the control gains for the modal amplitude and modal velocity. From Equation 12 and with the solution for the vibration rate $\dot{x}_{2}$, the angular response $\theta$ can be obtained in state form with $y_{1}=\theta$ and $y_{2}=\dot{\theta}$ as

$$
\left\{\begin{array}{l}
\dot{y}_{1}=y_{2} \\
\dot{y}_{2}=\frac{T_{c}+T_{d}}{2 a_{1}}-\frac{a_{5}}{2 a_{1}} \dot{x}_{2}-\frac{a_{4}}{2 a_{1}} \ddot{v}_{0}
\end{array}\right.
$$

In the following simulations, properties of the two beams are from Reference 12 for a $10-\mathrm{m}$ demonstration solar sail or from Reference 8 for a 106-m boom solar sail. Tables 1 and 2 summarize the properties and resulting natural frequencies for the first three modes of the beams.

Table 1. Single-Boom Properties for the 10-Meter Analytical Model

\begin{tabular}{ll}
\hline \hline Properties & \\
\hline Bending stiffness (EI) & $2660 \mathrm{Nm}^{2}$ \\
Mass per meter & $70 \mathrm{~g} / \mathrm{m}$ \\
Length & $7 \mathrm{~m}$ \\
Hub mass & $2.5 \mathrm{~kg}$ \\
Tip mass & $0.1 \mathrm{~kg}$ \\
Damping coefficient & 0.015 \\
First three natural frequencies & $1.639,28.448,51.389 \mathrm{~Hz}$ \\
\hline \hline
\end{tabular}

Current interest in the effects of wrinkling [14] lead to questions about effects of responding sail shape, prompting modeling of the sail disturbance as a harmonic function resulting from the shape of the sail as it responds in the first mode as 


$$
T_{d}=0.1 \cos (10.3 t) \quad t \leq t_{e} \text { and } \ddot{u}_{0}=0 \quad \ddot{v}_{0}=0
$$

For now, axial and thrust components of such a disturbance are assumed to be small in comparison to the torque disturbance, and are neglected. Future efforts will combine time-varying disturbances resulting from sail shape (see the next section for preliminary study) with this simulation.

Table 2. Single-Boom Properties for the Integrated Sail Model

\begin{tabular}{ll}
\hline Properties & Value \\
\hline Modulus & $1.24 \times 10^{11} \mathrm{~N}^{\mathrm{m}^{2}}$ \\
Density & $1908 \mathrm{~kg} / \mathrm{m}^{3}$ \\
Poisson's ratio & 0.3 \\
Outer radius & $0.22862 \mathrm{~m}$ \\
Wall thickness & $7.5 \times 10^{-6} \mathrm{~m}$ \\
Length & $106 \mathrm{~m}$ \\
Hub mass & $2.5 \mathrm{~kg}$ \\
Tip mass & $0.1 \mathrm{~kg}$ \\
Damping coefficient & 0.005 \\
First three natural frequencies & $0.060,0.378,1.066 \mathrm{~Hz}$ \\
\hline \hline
\end{tabular}

The first MATLAB [15] control simulation focused on the modal amplitude response induced by a disturbance torque without and with a feedback control torque. The simulation uses the properties from a $10-\mathrm{m}$ demonstration solar sail. For this simulation, the initial conditions are $V_{1}(0)=0 \mathrm{~m}, \dot{V}_{1}(0)=0 \mathrm{~m} / \mathrm{s}, \theta_{1}(0)=0 \mathrm{rad}$, and $\dot{\theta}_{1}(0)=0 \mathrm{rad} / \mathrm{s}$, the disturbance torque is $T_{d}=0.1 \cos (10.3 \mathrm{t})$ where $t \leq 1.5 \mathrm{~s}$ and the control torque is $T_{c}=K_{d} \dot{V}(t)$, where $t>0 s$ and $K_{d}=1 N \cdot s$.

Figures 4 and 5 present the results for two simulations. The first is uncontrolled, with the disturbance ending after 1.5 seconds. The second simulation has the same disturbance, but also includes a modal velocity feedback control applied for the entire simulation. The control is seen to damp the transient vibrational (modal amplitude) response at the beginning of the simulation and again when the harmonic disturbance discontinues. With larger gains, the vibration suppression is more immediate, as expected. Figure 6 is the same simulation, but with the gain eight times larger. 


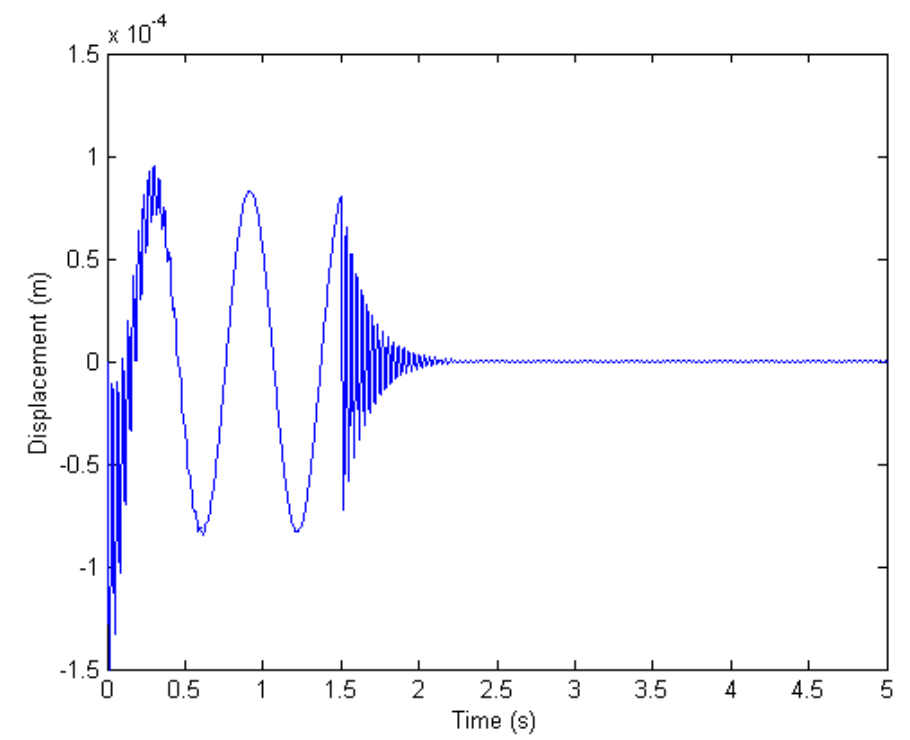

Figure 4. Modal amplitude response with disturbance $T_{d}=0.1 \cos (10.3 t)$ where $t \leq 1.5 \mathrm{~s}$ and no feedback control.

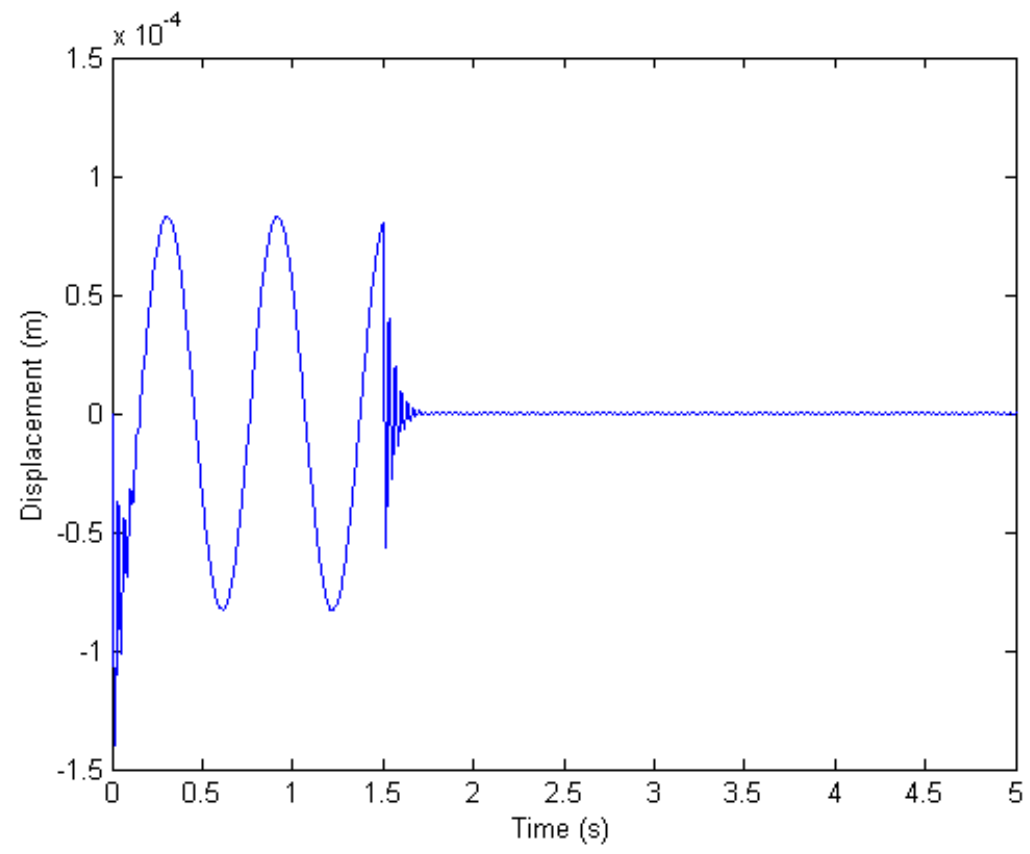

Figure 5. Modal amplitude response with disturbance $T_{d}=0.1 \cos (10.3 t)$ where $t \leq 1.5 \mathrm{~s}$ and feedback control $T_{c}=K_{d} \dot{V}(t)$, where $t>0 s$ and $K_{d}=1 N \cdot s$. 


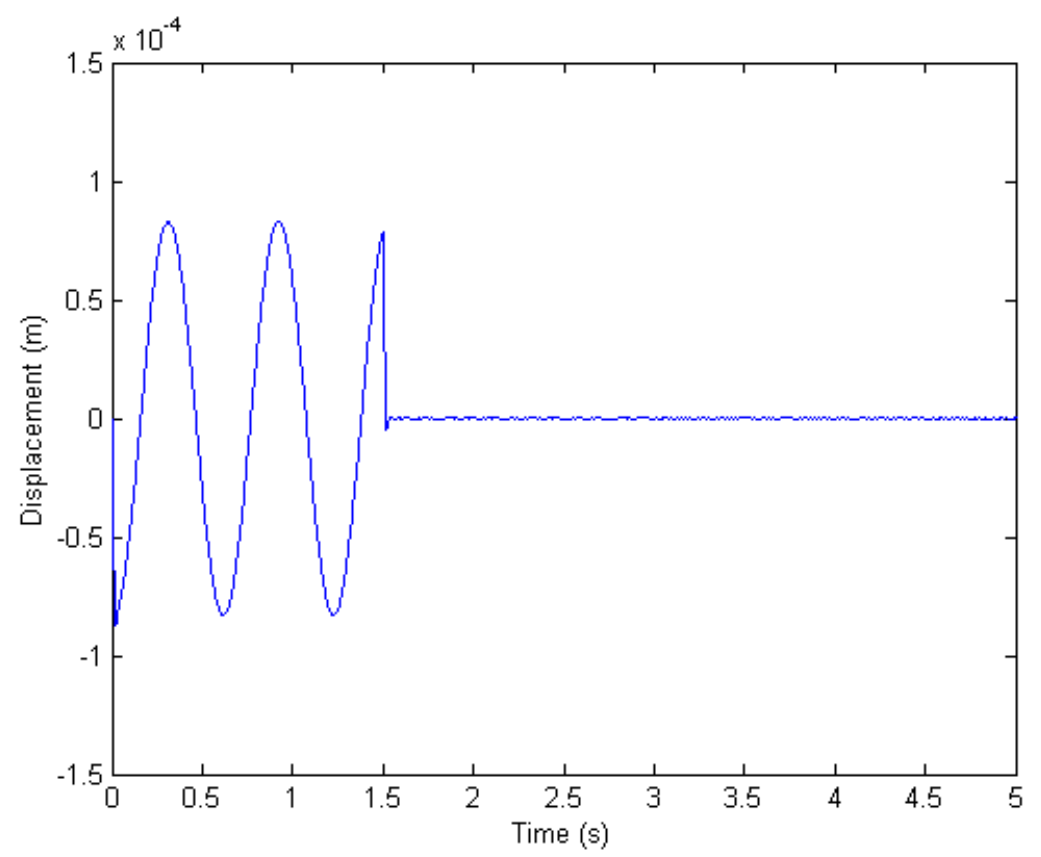

Figure 6. Modal amplitude response with disturbance $T_{d}=0.1 \cos (10.3 t)$ where $t \leq 1.5 \mathrm{~s}$ and feedback control

$$
T_{c}=K_{d} \dot{V}(t) \text {, where } t>0 s \text { and } K_{d}=8 N \cdot s .
$$

The second simulation focuses on the coupled angular and modal responses resulting from an angular rate initial condition. This simulation is without solar radiation or other disturbance torques. The example uses properties from a 106-m boom integrated solar sail. For this simulation, the initial conditions are $V_{1}(0)=0 \mathrm{~m}, \dot{V}_{1}(0)=0 \mathrm{~m} / \mathrm{s}$, $\theta_{1}(0)=0 \mathrm{rad}$, and $\dot{\theta}_{1}(0)=0 \mathrm{rad} / \mathrm{s}$, and the control torque is $T_{c}=K_{a}\left(\theta(t)-\theta_{0}\right)+K_{b} \dot{\theta}(t)$, with $K_{a}=-1000$, $K_{b}=-100$. The control law is a linear feedback control to move the sail to the reference position $(\theta=0)$ and reduce the angular rate to zero. Results are presented in Figures 7 through 9.

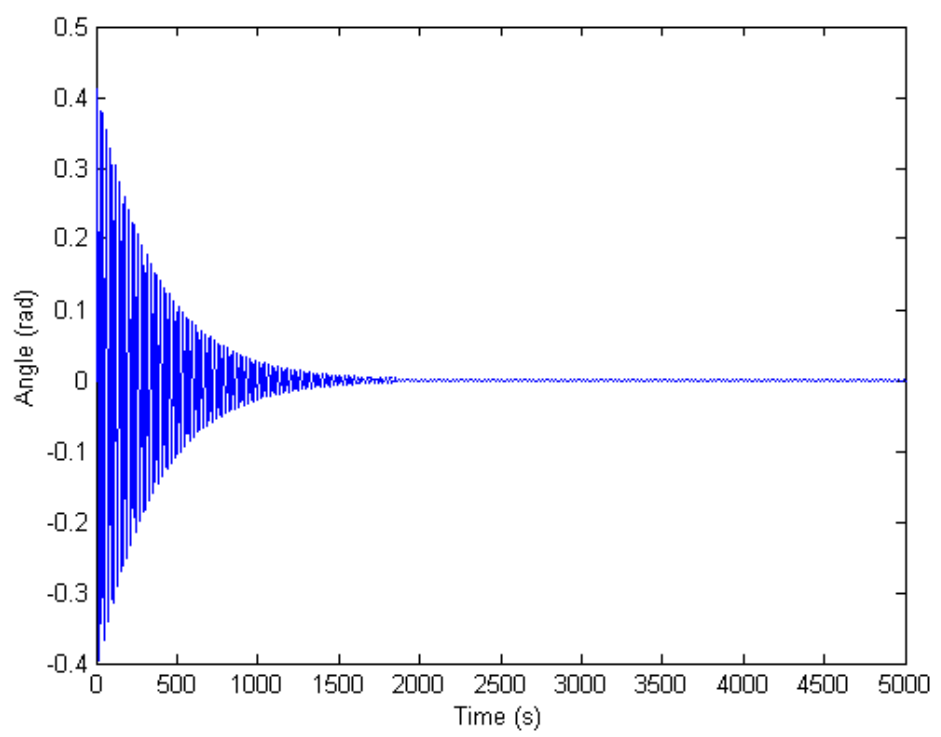

Figure 7. Controlled response of a 106-m boom model from angular rate initial conditions: angular response. 


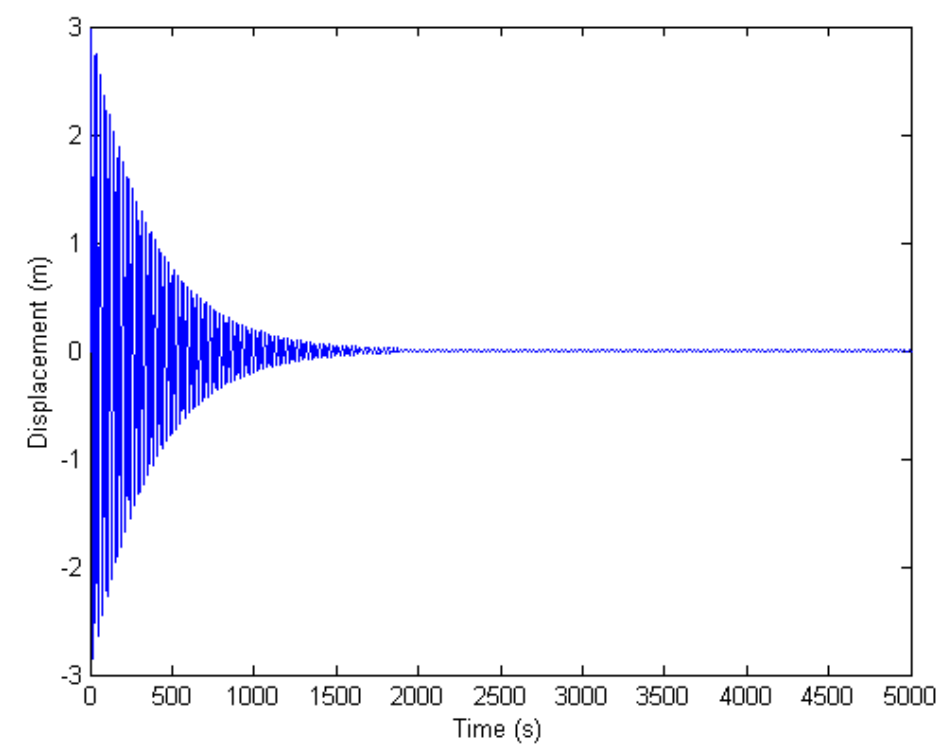

Figure 8. Controlled response of a 106-m boom model from angular rate initial conditions: modal response.

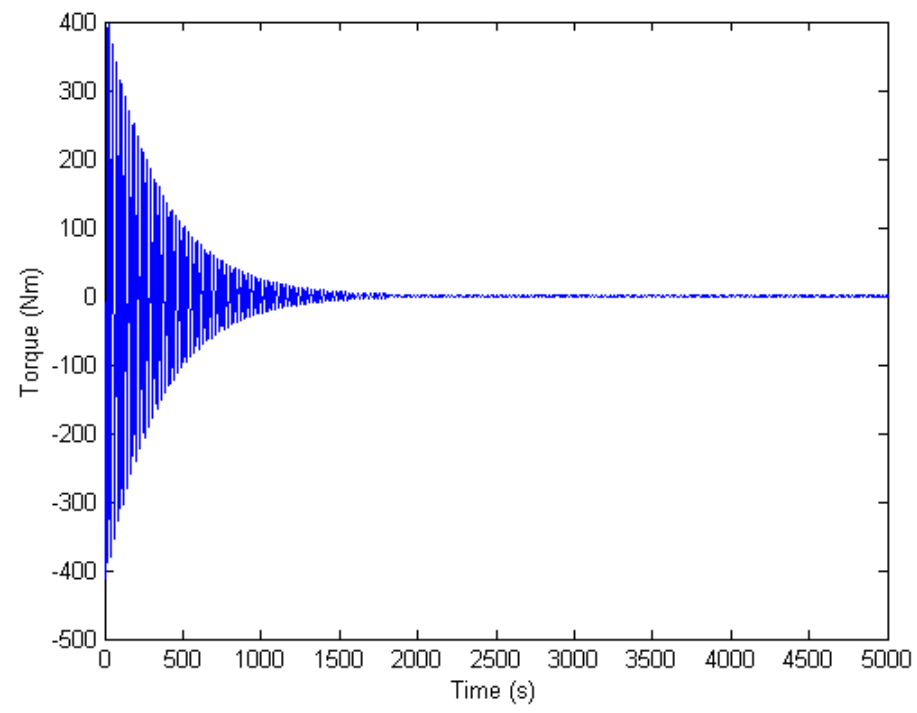

Figure 9. Controlled response of a 106-m boom model from angular rate initial conditions: control torque.

The next simulations change the scenario: the disturbance now persists throughout the 10 -second simulation and the control is initiated at time $t=1.5$ seconds. Furthermore, the model damping is decreased to $c_{1}=c_{2}=0.005 \mathrm{~N} \cdot \mathrm{s} / \mathrm{m}$. Figures 10 and 11 present the modal amplitude response and the angular position response, respectively, for no control.

Figures 12 and 13 present the modal amplitude and the angular position with a feedback control with only modal amplitude (no velocity) feedback. Note that to have any influence, the gain for the position feedback (modal amplitude) must be large since the modal amplitudes are very small. To further illustrate this point, the same simulation is run, but with the addition of a small velocity feedback term. Figures 14 and 15 are plots of the modal amplitude response and the angular position response, respectively. A significant reduction of the modal amplitude is seen in Figure 14 compared to Figure 12. The results of both controlled simulations show a linearly increasing angular position after the control is initiated. 
To control the angular position of the flexible solar sail, a different control law is implemented. For these simulations, the harmonic disturbance is not present. First, the orientation angle is controlled to move the solar sail from an angular position of $0^{\circ}$ to an angular position of $5^{\circ}$. The control torque is a combination of a constant torque to initiate the motion and an angular rate feedback to stop the maneuver. Figures 16 and 17 present the modal angular position response and modal amplitude time histories for this maneuver, respectively. Their control torques are represented as below

$$
T_{c}=\left\{\begin{array}{l}
0 \quad t \leq 2 \mathrm{~s}, \\
0.2 \mathrm{Nm} \quad t>2 \mathrm{~s} \text { and } \theta \leq 4.03^{\circ} \\
K_{a} \dot{\theta}(t) \quad \theta>4.03^{\circ}, K_{a}=-50 \mathrm{Nms} / \mathrm{rad}
\end{array}\right.
$$

In the final simulation of this section, the angle $\theta_{0}$ is controlled in a maneuver from $8^{\circ}$ to $0^{\circ}$ to $-8^{\circ}$ with control torque designed as a proportional feedback of the angular position error and the angular rate, $T_{c}=K_{a}\left(\theta(t)-\theta_{0}\right)+K_{b} \dot{\theta}(t)$ with $K_{a}=-20 \mathrm{Nm} / \mathrm{rad}, K_{b}=-50 \mathrm{Nms} / \mathrm{rad}$. Figures 18 through 20 present respectively the angular position, the boom tip mass response and the torque time histories for this maneuver. Note that if the gain $K_{a}$ is less than zero and greater than $-20 \mathrm{Nm} / \mathrm{rad}$, the control torque would be smaller, but the control time would be longer.

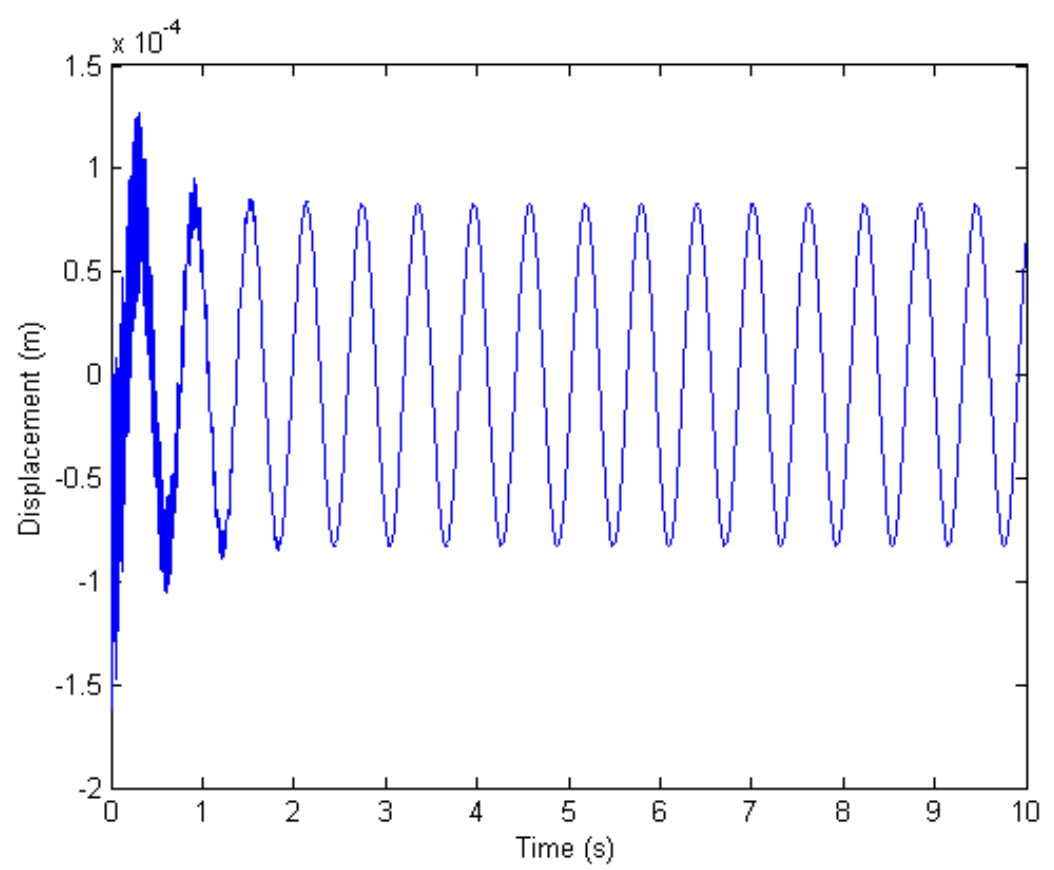

Figure 10. Modal amplitude response with disturbance $T_{d}=0.1 \cos (10.3 t)$ where $t \leq 10 \mathrm{~s}$ and no control. 


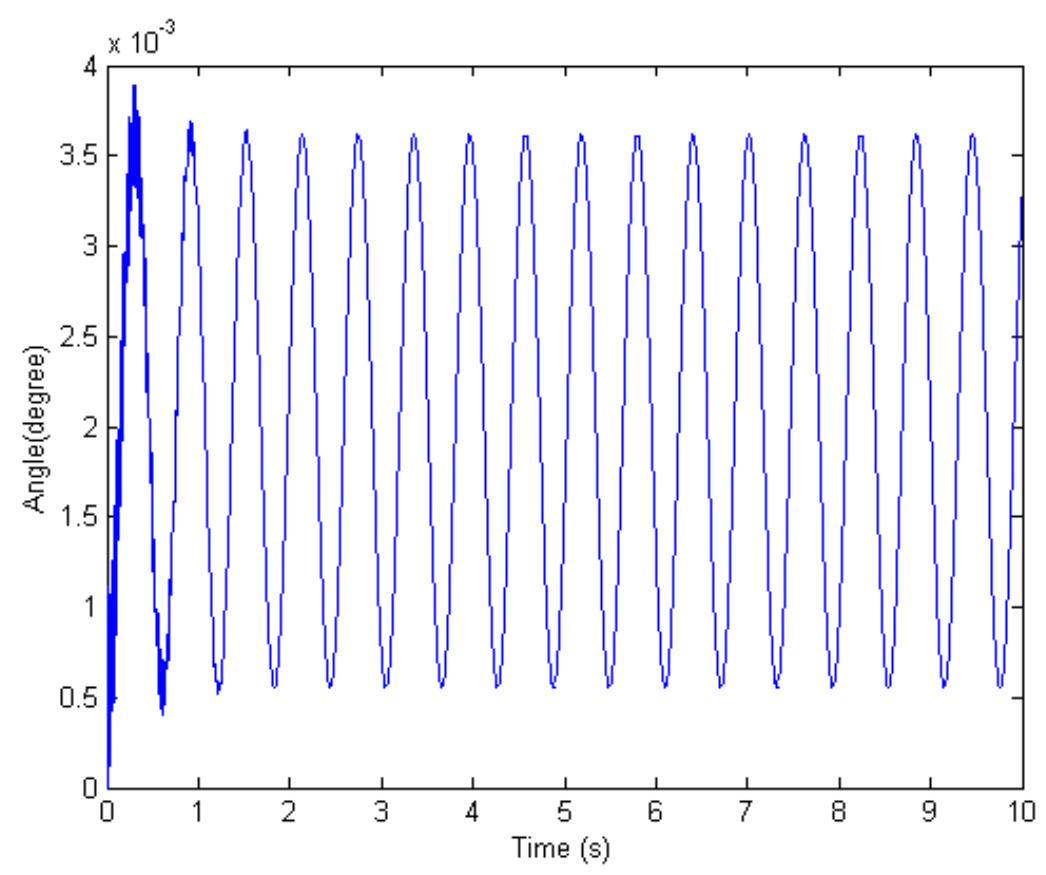

Figure 11. Angular position response with disturbance $T_{d}=0.1 \cos (10.3 t)$ where $t \leq 10 \mathrm{~s}$ and no control.

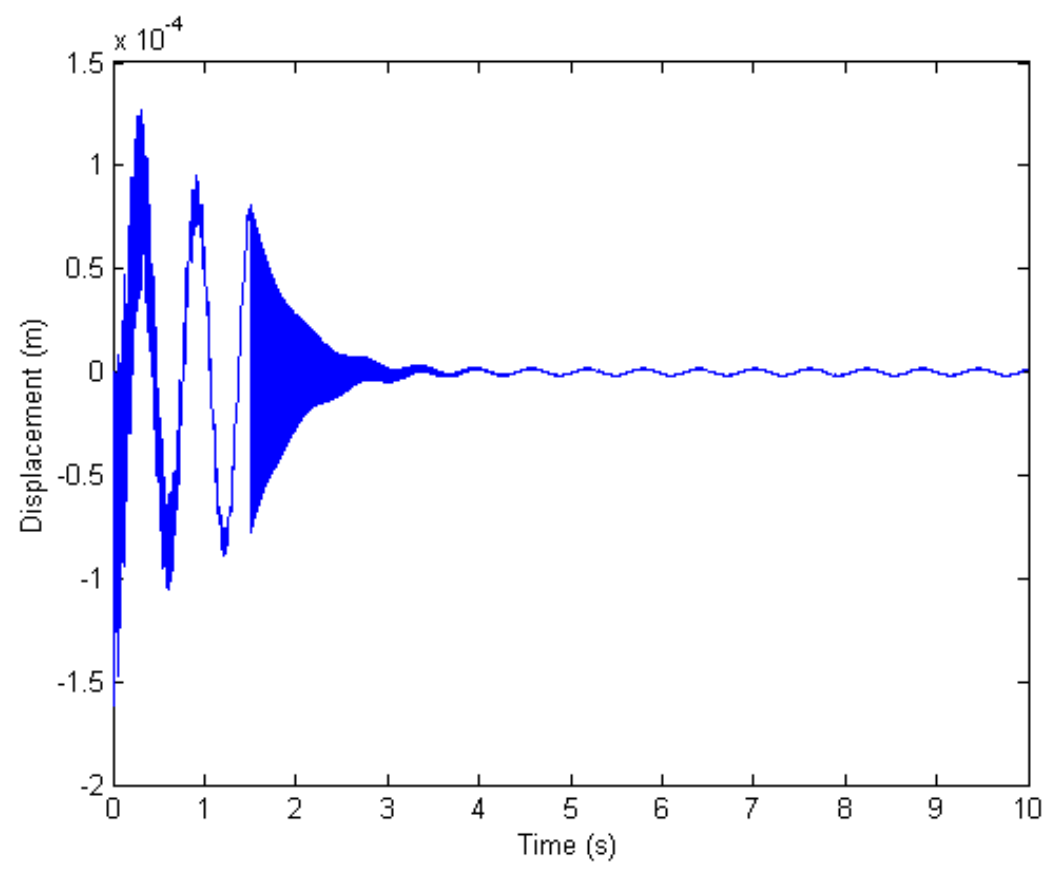

Figure 12. Modal amplitude response with disturbance $T_{d}=0.1 \cos (10.3 t)$, where $t \leq 10 \mathrm{~s}$ and feedback control $T_{c}=K_{p} V(t)+K_{d} \dot{V}(t)$, where $t>1.5 s, K_{p}=60000 N, K_{d}=0 N \cdot s$. 


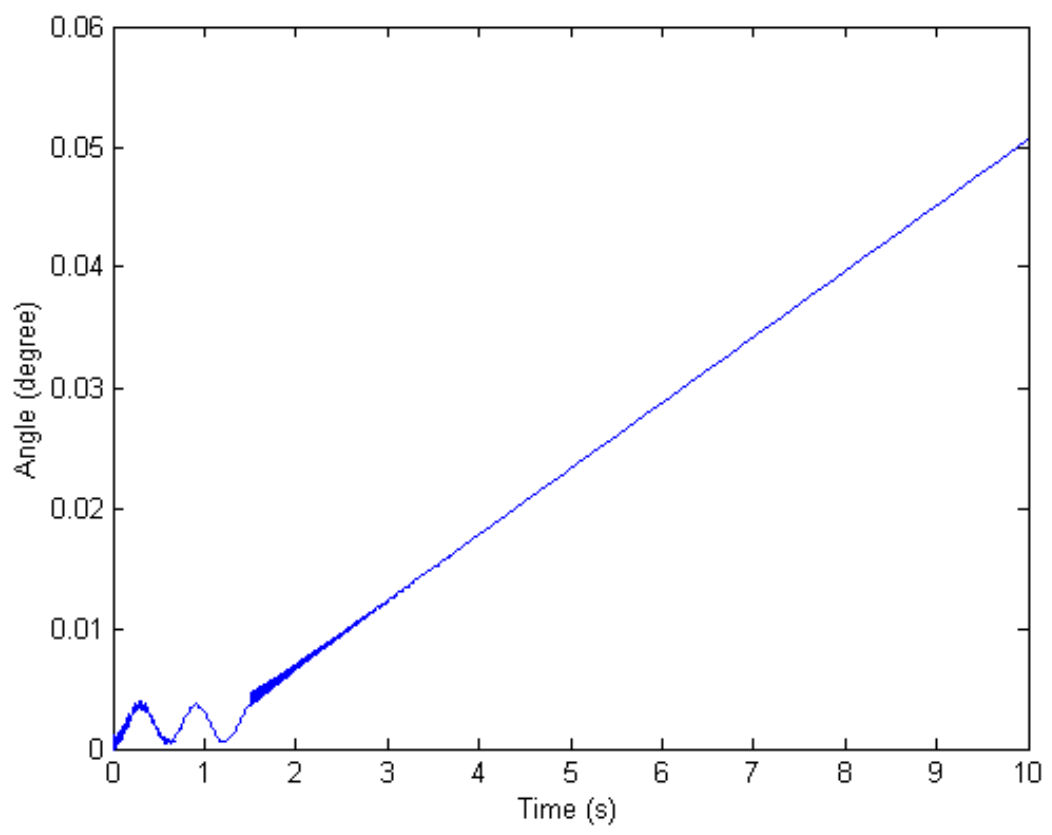

Figure 13. Angular position response with disturbance $T_{d}=0.1 \cos (10.3 t)$, where $t \leq 10 \mathrm{~s}$ and feedback control $T_{c}=K_{p} V(t)+K_{d} \dot{V}(t)$, where $t>1.5 \mathrm{~s}, K_{p}=60000 \mathrm{~N}, K_{d}=0 \mathrm{~N} \cdot \mathrm{s}$.

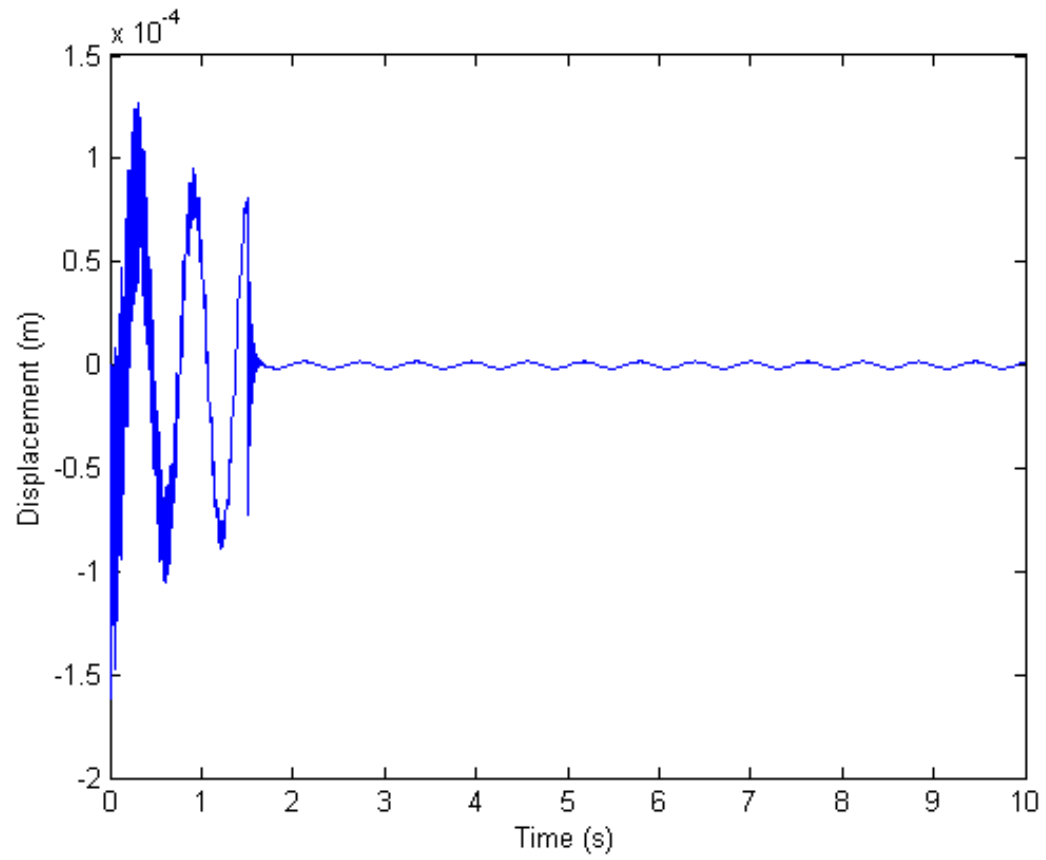

Figure 14. Modal amplitude response with disturbance $T_{d}=0.1 \cos (10.3 t)$, where $t \leq 10 \mathrm{~s}$ and feedback control $T_{c}=K_{p} V(t)+K_{d} \dot{V}(t)$, where $t>1.5 \mathrm{~s}, K_{p}=60000 \mathrm{~N}, K_{d}=2 \mathrm{~N} \cdot \mathrm{s}$. 


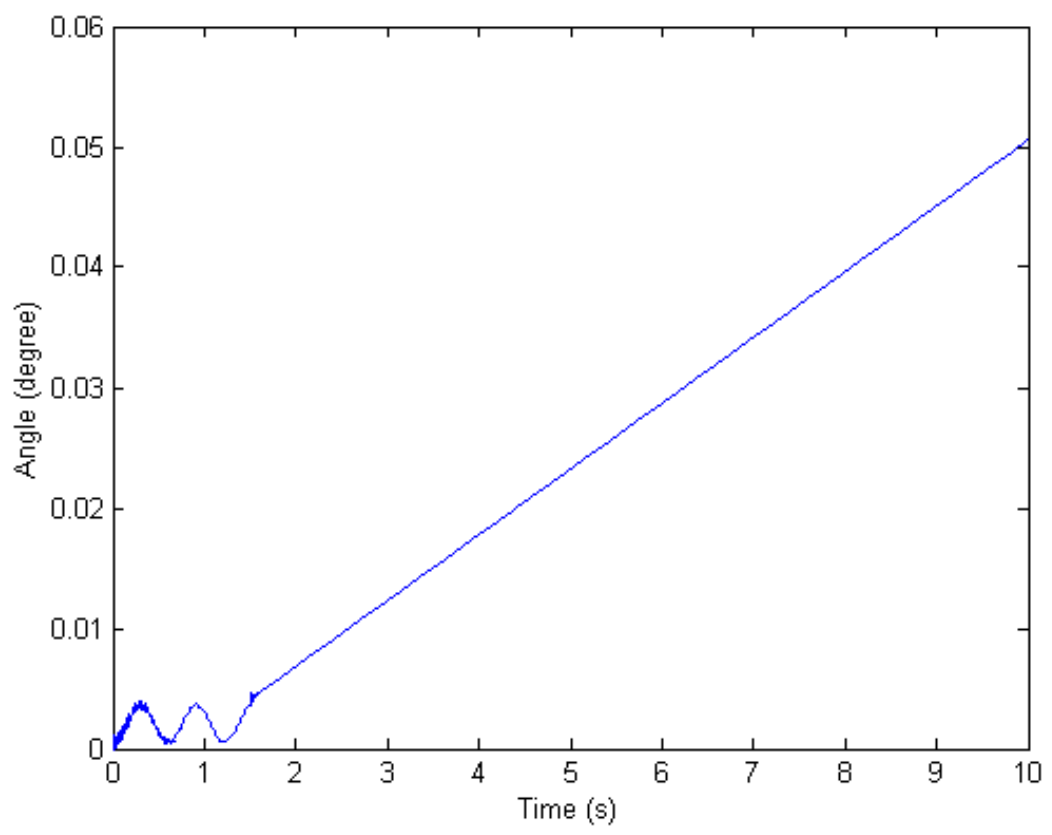

Figure 15. Angular position response with disturbance $T_{d}=0.1 \cos (10.3 t)$, where $t \leq 10 \mathrm{~s}$ and feedback control $T_{c}=K_{p} V(t)+K_{d} \dot{V}(t)$, where $t>1.5 \mathrm{~s}, K_{p}=60000 \mathrm{~N}, K_{d}=2 \mathrm{~N} \cdot \mathrm{s}$.

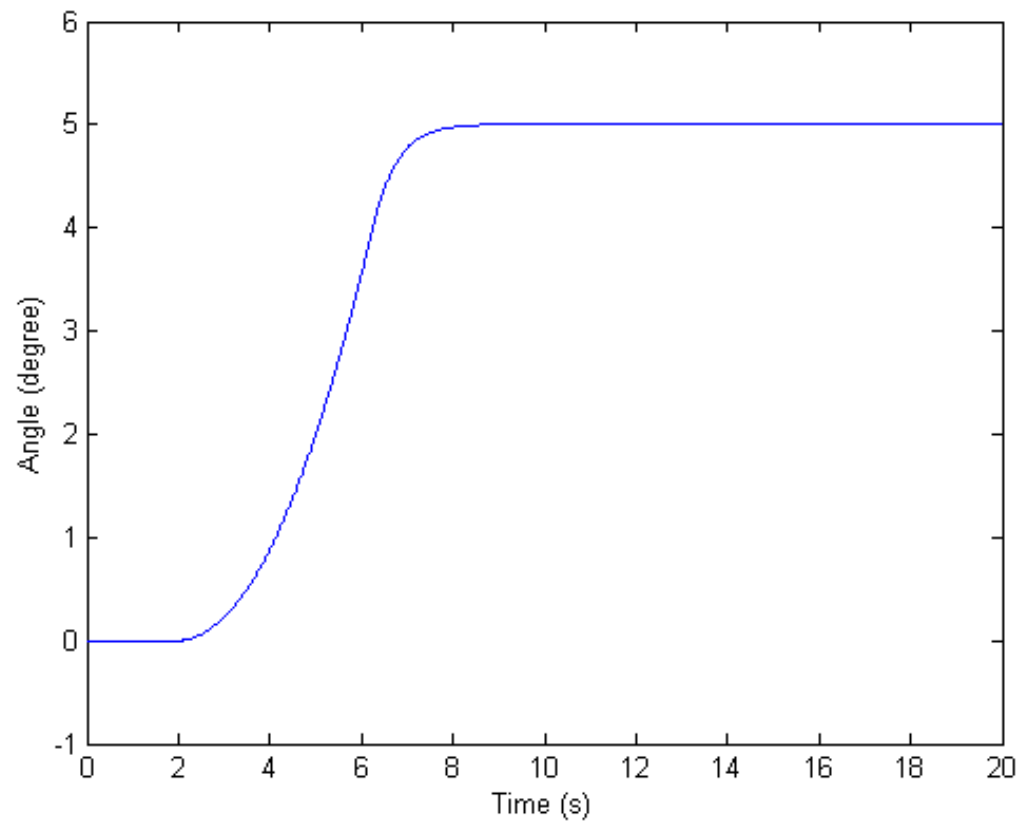

Figure 16. Angular position response for angular positioning maneuver $\theta_{0}$ from $0^{\circ}$ to $5^{\circ}$ with control. 


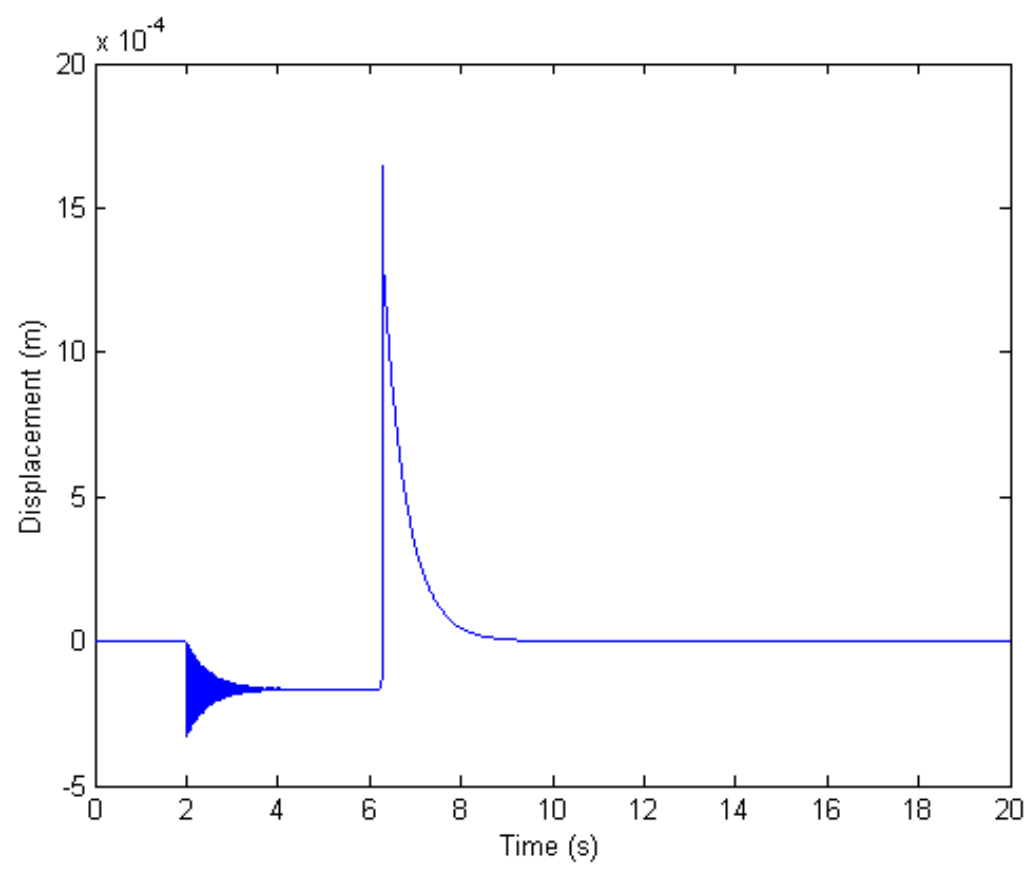

Figure 17. Modal amplitude response for angular positioning maneuver $\theta_{0}$ from $0^{\circ}$ to $5^{\circ}$ with control.

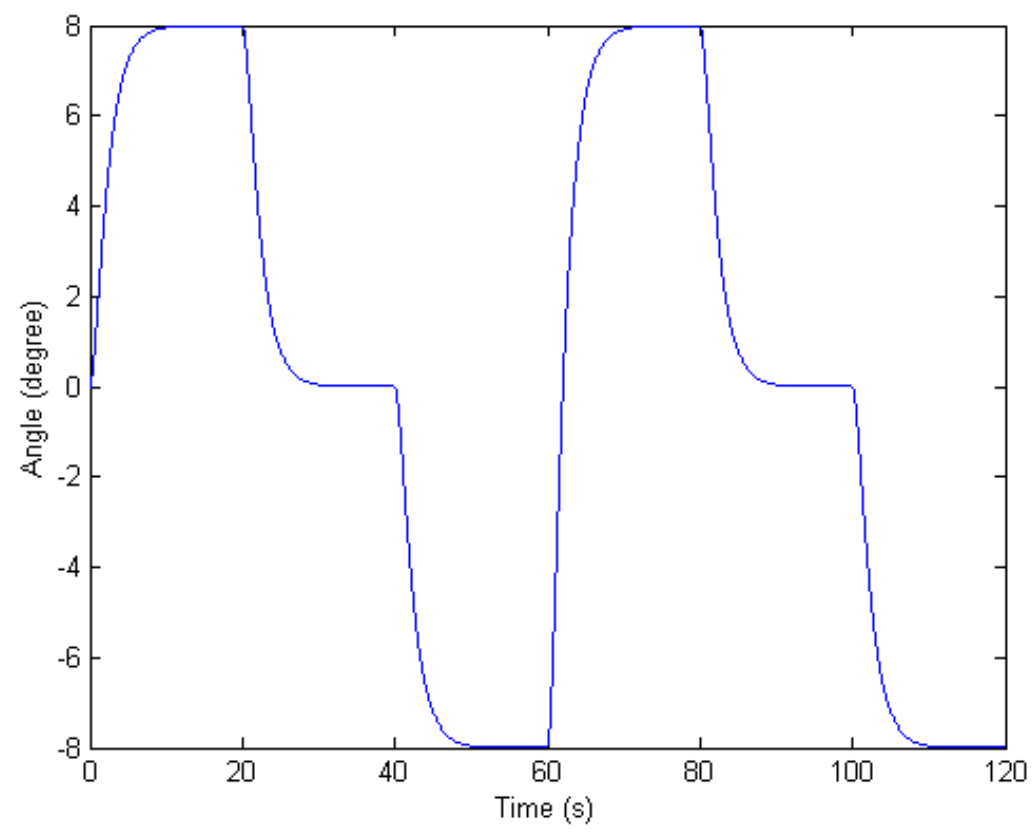

Figure 18. Angular position response for angular positioning maneuver $\theta_{0}$ from $8^{\circ}$ to $0^{\circ}$ to $-8^{\circ}$ with control $T_{c}=K_{a}\left(\theta(t)-\theta_{0}\right)+K_{b} \dot{\theta}(t)$ where $K_{a}=-20 \mathrm{Nm} / \mathrm{rad}, K_{b}=-50 \mathrm{Nms} / \mathrm{rad}$. 


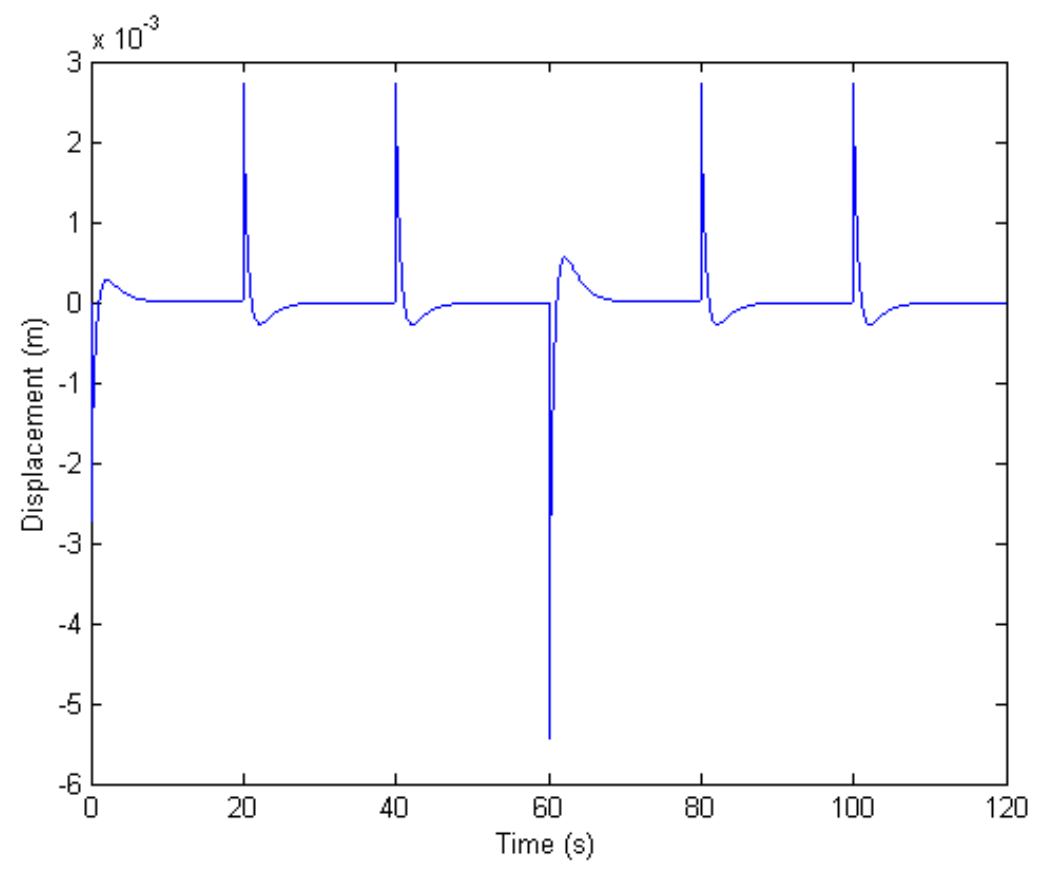

Figure 19. Boom tip displacement response for angular positioning maneuver $\theta_{0}$ from $8^{\circ}$ to $0^{\circ}$ to $-8^{\circ}$ with control $T_{c}=K_{a}\left(\theta(t)-\theta_{0}\right)+K_{b} \dot{\theta}(t)$ where $K_{a}=-20 \mathrm{Nm} / \mathrm{rad}, K_{b}=-50 \mathrm{Nms} / \mathrm{rad}$.

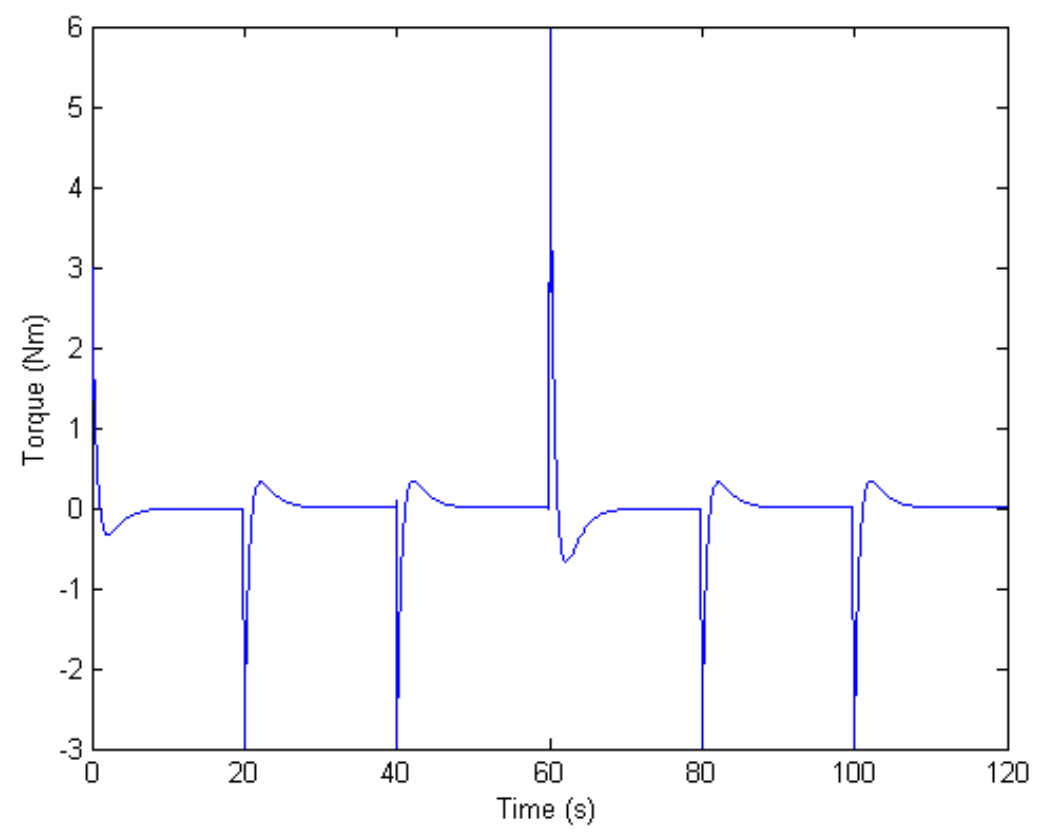

Figure 20. Control torque for angular positioning maneuver $\theta_{0}$ from $8^{\circ}$ to $0^{\circ}$ to $-8^{\circ}$ with control $T_{c}=K_{a}\left(\theta(t)-\theta_{0}\right)+K_{b} \dot{\theta}(t)$ where $K_{a}=-20 \mathrm{Nm} / \mathrm{rad}, K_{b}=-50 \mathrm{Nms} / \mathrm{rad}$. 


\section{Solar Radiation Disturbance}

Disturbances acting on the hub can be specified independent of the sail response or can be computed based on the response shape of the solar sail. An algorithm was developed and implemented in MATLAB to determine the solar radiation pressure disturbance effects. The algorithm first divides the phenomena model sail into $n$ elements each of equal length $M$, and then calculates the displacement of each element from the initial flat sail plane $(\vec{D})$ according to the mode shape function corresponding to the current time step. The distance from the center of each element $a$ to the center of the sun $(\vec{r})$ is calculated using the following formula:

$$
\vec{r}(a)=R-[(M((0.5 n+1)-a)-0.5 M] \cos (S)+\vec{D}(a)
$$

where the constants are as follows: $R=150 \times 10^{9}$ meters is the distance from the Sun at $1 \mathrm{AU}$, where the solar intensity is $I=4 \times 10^{26}$ watts, and the speed of light is $C=3 \times 10^{8}$ meters per second, $S$ is the counter-clockwise angle from sail plane to line connecting the sail hub to the center of the Sun, and $W$ is the width of each element in meters. See Figure 21 for geometric definitions.

The MATLAB script calculates the solar intensity $\left(i\right.$ in N/(m-s)) and force of the Sun $\left(f\right.$ in $\left.\mathrm{N} / \mathrm{m}^{2}\right)$ due to that intensity at each element $a$ using the following equations

$$
i(a)=\frac{I}{4 \pi \vec{r}(a)^{2}} \quad f(a)=\frac{2 i(a)}{C}
$$

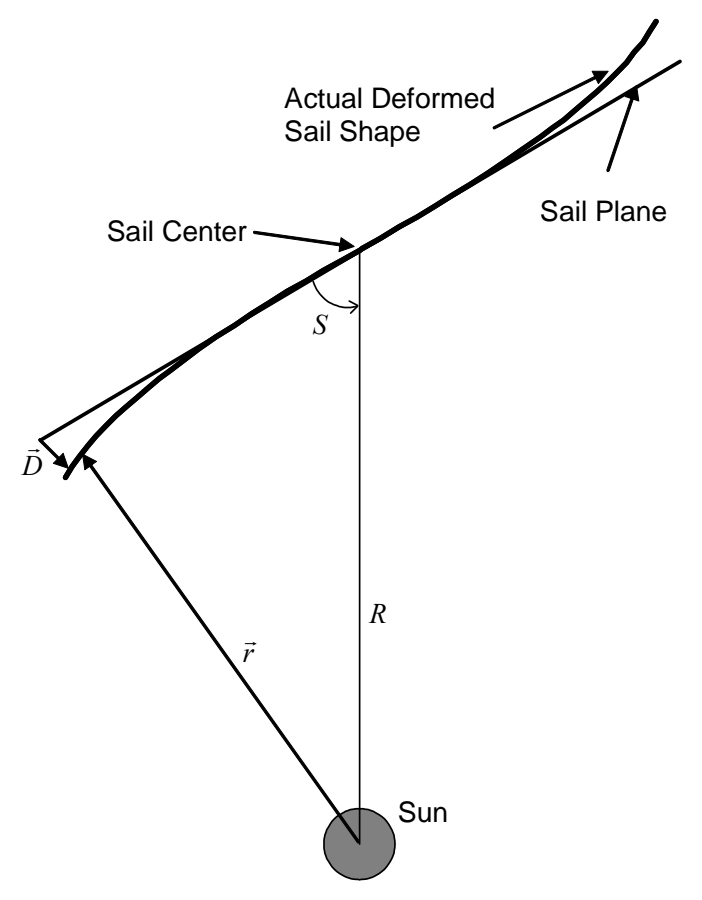

Figure 21. Solar radiation schematic and parameters

As shown in Figure 22, the Sun force at each element is calculated by the projection of each element onto the sail plane normal to the Sun. The analytical model shape is approximated by a discrete number of straight line members. The slope of each member is used in the torque calculation, but not in the force calculation below to ensure that any disturbance torque results from the differential in the distance of opposite parts of the sail to the Sun, and not the approximation. The Sun force $(F)$ is therefore calculated in Newtons from Newtons per square meter in $f$ above. The slope of each element is used to calculate the angle from the element normal to the sail plane (eleangle), where 


$$
\begin{aligned}
& F(a)=f(a) m \sin (S) W \\
& \text { eleangle }(a)=\pi-\pi / 2-\arctan (\text { eleslope }(a))
\end{aligned}
$$

The perpendicular moment arm of the force vector acting along the element normal is calculated by first finding $\theta$, the angle from the sail plane normal to the line from the center of the element to the center of the sail, $\ell$, where $X$ is the $\mathrm{x}$-distance from the center of the sail to the center of the element. The angle $\beta$ is the angle from $\ell$ to the "bottom" of the right triangle, or the line connecting the perpendicular moment arm to the center of the element, where

$$
\begin{aligned}
& \theta=\arctan (D(a) / X(a)) \\
& \text { if eleangle }(a)>\pi / 2 \\
& \beta(a)=\pi-\operatorname{atan}(D(a) / X(a)) \text { - eleangle }(a) \\
& \text { elseif eleangle }(a)<\pi / 2 \\
& \beta(a)=\operatorname{atan}(D(a) / X(a))+\text { eleangle }(a) \\
& \text { else } \\
& \beta(a)=\pi / 2 ;
\end{aligned}
$$

The length of the perpendicular moment arm is calculated as $\sin (\beta)$ multiplied by the length of $\ell$. To enforce the correct sign on the moment calculation, the length of the moment arm is multiplied by the sign of $X$ in Equation 19. This ensures that forces on opposite sides of the sail hub produce opposite signed torques.

$$
\text { elemomentarm }(a)=\sqrt{X(a)^{2}+D(a)^{2}} \sin (\beta(a)) \operatorname{sign}(X(a))
$$

The total disturbance torque $T_{d}$ is then the sum of the force on each element $F$ is multiplied by the perpendicular moment arm summed over the entire sail.

$$
T_{d}=\sum_{a=1}^{n} F(a) \text { elemomentarm }(a)
$$

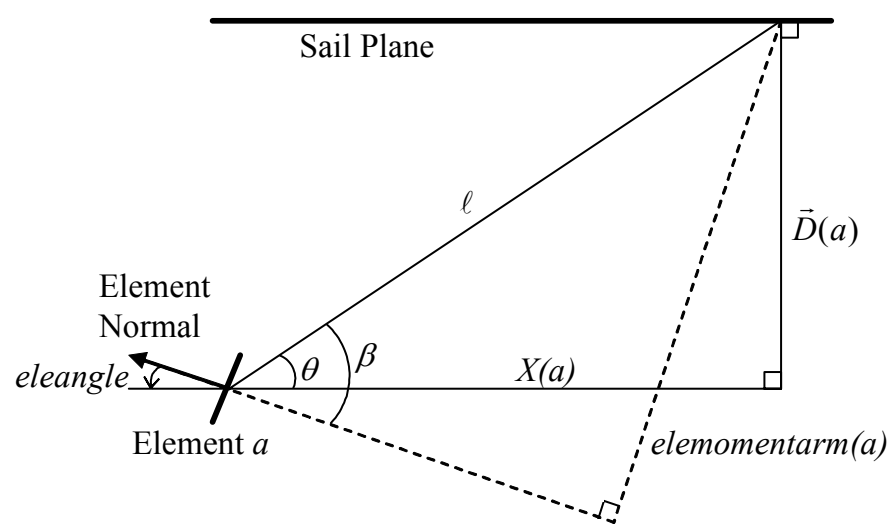

Figure 22. Solar radiation disturbance computation parameters 
A study of solar radiation effects was conducted first to examine the orientation of the sail with respect to the sun, the amplitude of the modal response and trends in the resulting disturbance torque. The geometric and material properties used for this study were for a $10-\mathrm{m}$ test article sail, allowing efficient computation of the trends in contrast to the time required to compute trends with a larger sail model. The trends seen here are valid for larger models. Figure 23 presents the results of this study, and we see that the largest disturbance torques result when the sail plane is oriented 30 degrees from perpendicular to the sun line. When the sail plane is perpendicular to the sun line (at 0 degrees), the disturbance increases with the amplitude of the modal response. When the sail is oriented parallel to the sun line (at 90 degrees), the disturbance effects are independent of the shape of the sail response.

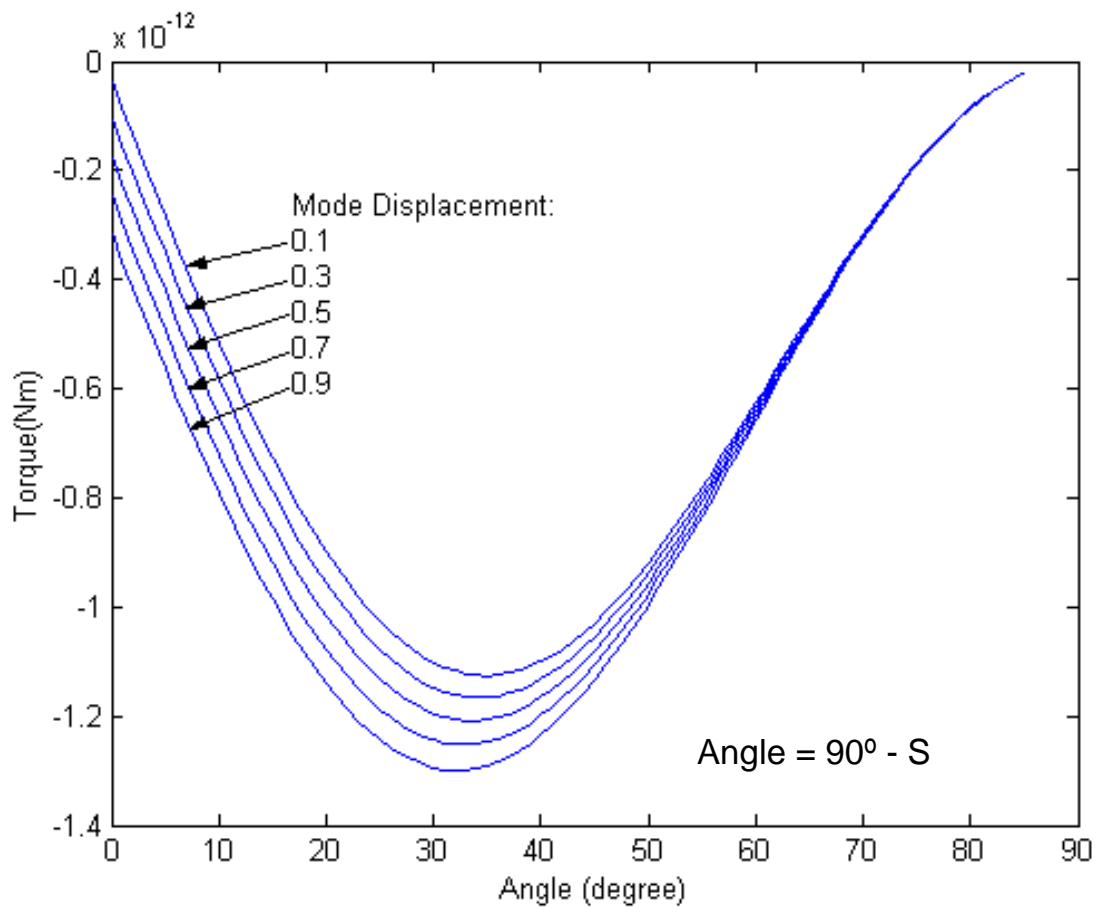

Figure 23. Disturbance torque at different angles between solar sail and sun vector (7-m boom)

The next simulation focused on the angular response induced by solar radiation disturbance torque resulting from an initial modal displacement condition. The example uses properties from a 10-m demonstration solar sail with a boom length of $7 \mathrm{~m}$. Due to the order of magnitude smaller size of the sail in this model, the radiation intensity is increased accordingly to $4 \times 10^{36} w$. The distance from the Sun is $1.5 \times 10^{11} \mathrm{~m}$; the speed of light is $3 \times 10^{8} \mathrm{~m} / \mathrm{s}$. For this simulation, the initial conditions are $V_{1}(0)=0.1 \mathrm{~m}, \dot{V}_{1}(0)=0 \mathrm{~m} / \mathrm{s}, \theta_{1}(0)=0 \mathrm{rad}$, and $\dot{\theta}_{1}(0)=0 \mathrm{rad} / \mathrm{s}$, the disturbance torque is computed using the solar radiation disturbance model and the control torque is $T_{c}=K_{a}\left(\theta(t)-\theta_{0}\right)+K_{b} \dot{\theta}(t)$ with $K_{a}=-100, K_{b}=-10$. The angular response without control is seen in Figure 24. After a long time, a change of angular orientation is seen. The angular response with control is seen to diminish in Figure 25a), along with the control torque in Figure 25b). 


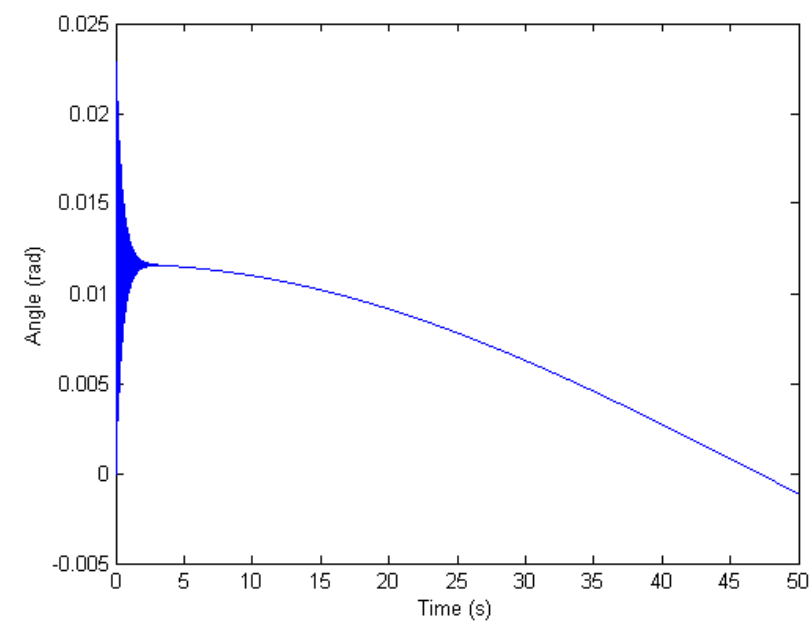

Figure 24. Uncontrolled response of a 10-m sail to solar radiation disturbance.

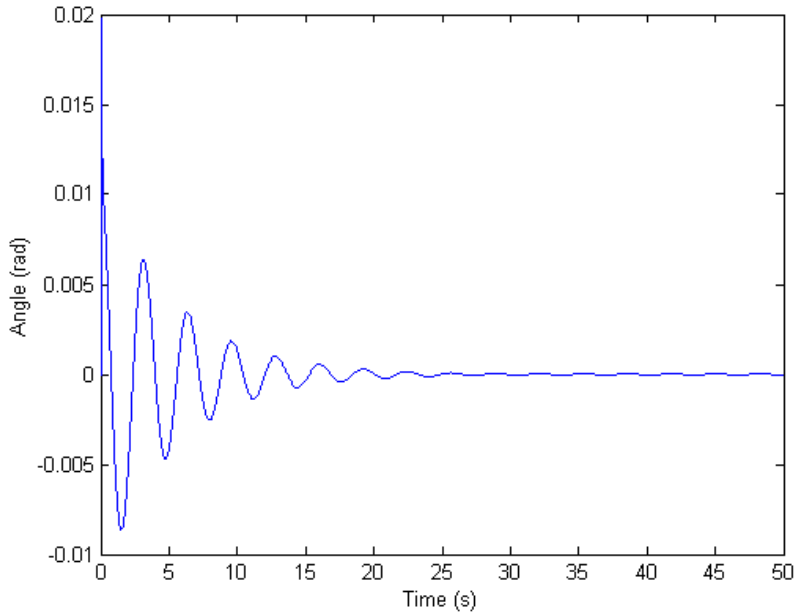

a) Angular position response

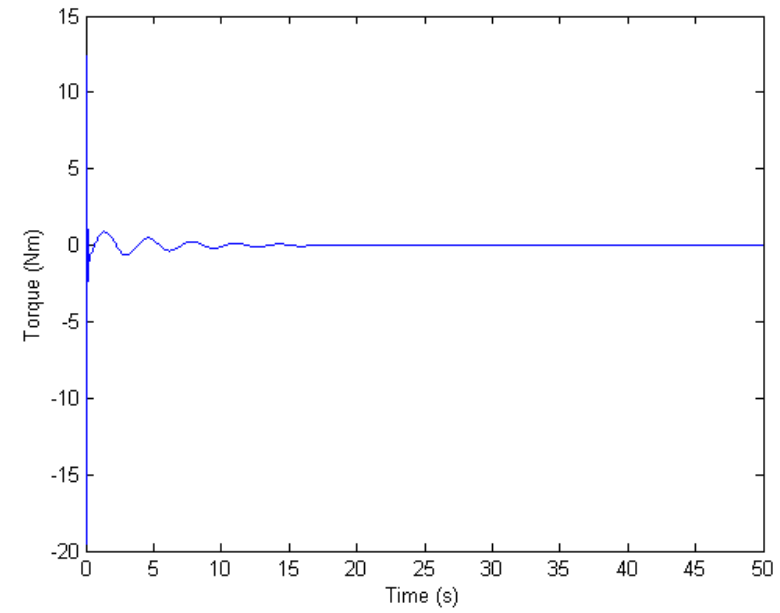

b) Control torque

Figure 25. Controlled response of a 10-m sail to solar radiation disturbance. 
The next simulation presented focused on the angular response induced by solar radiation disturbance torque resulting from an angular rate initial condition. The example uses properties from a 106-m boom solar sail. The initial angle between the sun and solar sail surface is 30 degrees. For this simulation, the initial conditions are $V_{1}(0)=0 m, \dot{V}_{1}(0)=0 \mathrm{~m} / \mathrm{s}, \theta_{1}(0)=0 \mathrm{rad}$, and $\dot{\theta}_{1}(0)=0.1 \mathrm{rad} / \mathrm{s}$, the disturbance torque is computed using the solar radiation model and there is no control torque applied. Figure 26a) presents the boom tip displacement of the uncontrolled simulation, while Figure 26b) presents the angular displacement. Note that the steady state angular orientation is not zero.

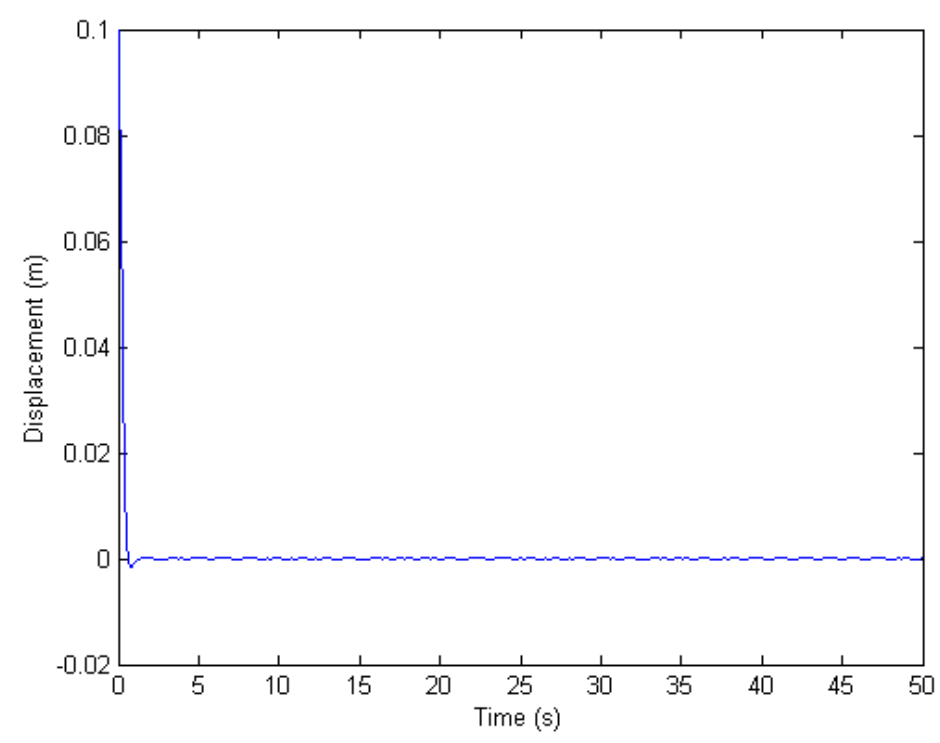

a) Boom tip displacement

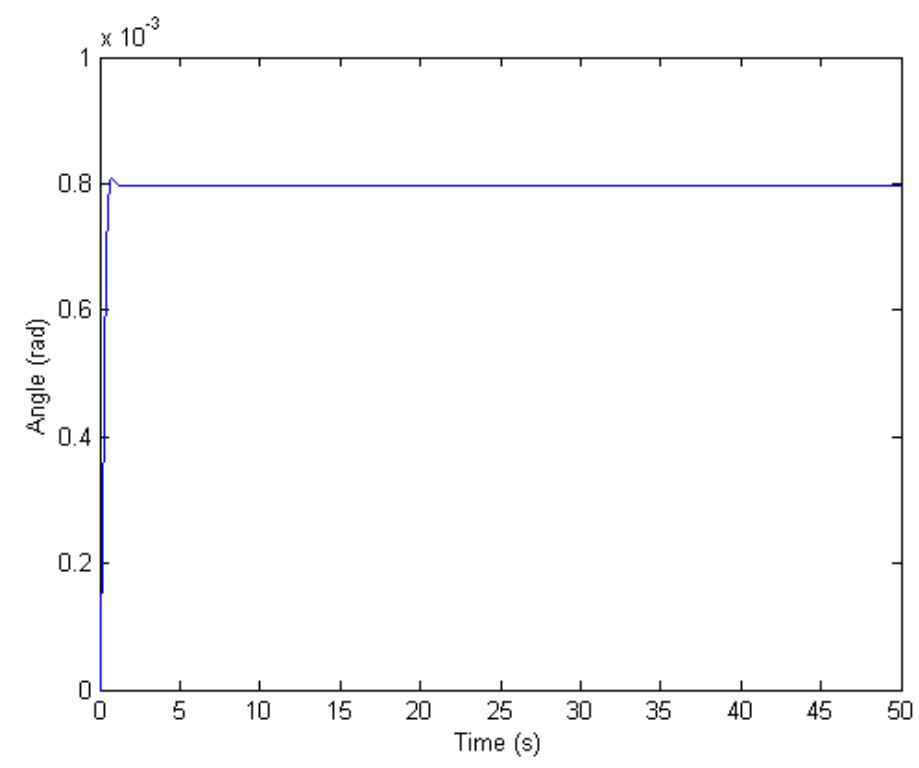

b) Angular position

Figure 26. Uncontrolled response of a 106-m boom sail to solar radiation disturbance.

The next simulation is the same as the previous one, but with control. It focused on angular response induced by solar radiation disturbance torque resulting from an angular rate initial condition. The example uses properties from 
a $106-\mathrm{m}$ boom solar sail. The distance from the Sun is $1.5 \times 10^{11} \mathrm{~m}$; and the speed of light is $3 \times 10^{8} \mathrm{~m} / \mathrm{s}$. For this simulation, the initial conditions are $V_{1}(0)=0 \mathrm{~m}, \dot{V}_{1}(0)=0 \mathrm{~m} / \mathrm{s}, \theta_{1}(0)=0 \mathrm{rad}$, and $\dot{\theta}_{1}(0)=0.1 \mathrm{rad} / \mathrm{s}$, the disturbance torque is computed using the solar radiation model and the control torque is $T_{c}=K_{a}(\theta(t)-0)+K_{b} \dot{\theta}(t)$, where $K_{a}=-100, K_{b}=-100$. Figure 27 presents the results of this simulation.

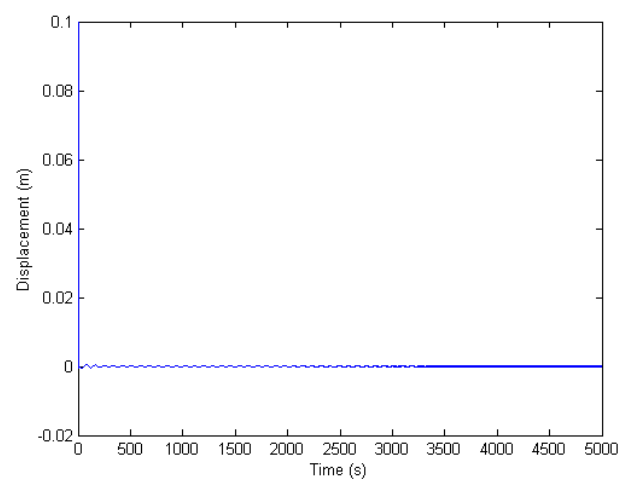

a) Boom tip displacement

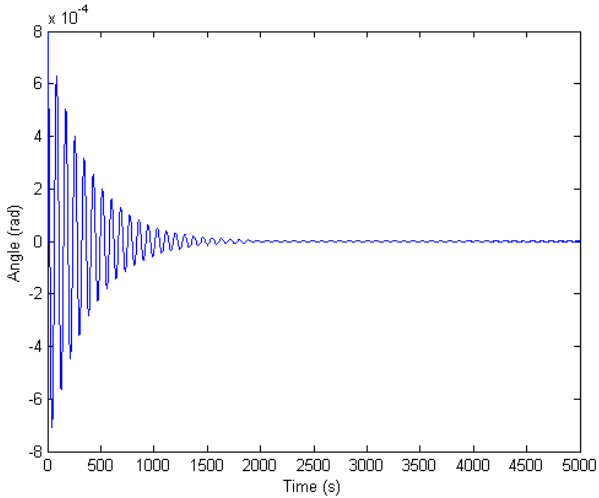

b) Angular position

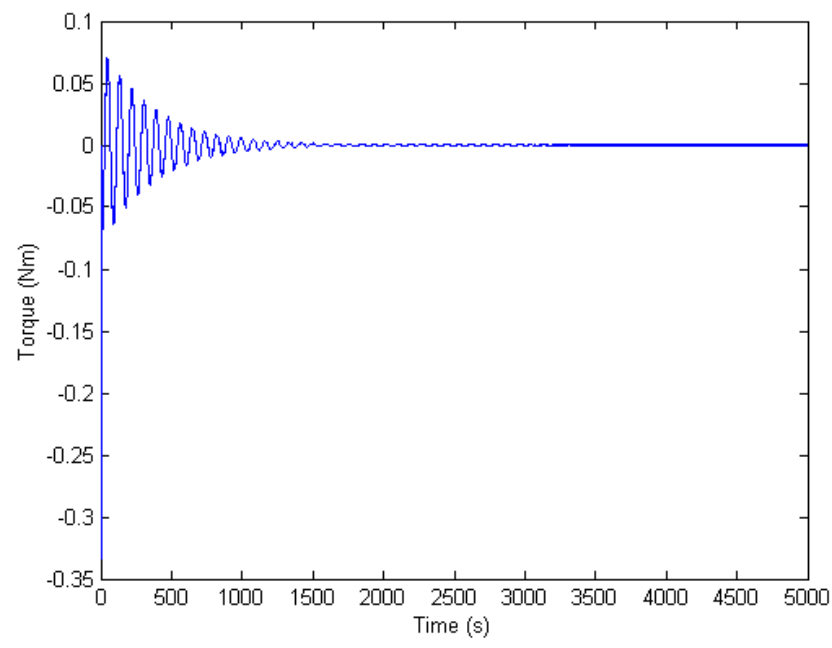

c) Control torque

Figure 27. Controlled response of a 106-m boom sail with solar radiation disturbance: modal, angular, and control torque.

\section{Finite Element Modeling Approach}

The complicated dynamics of large solar sails may best be modeled using the finite element method. However, use of high-fidelity FE models in transient controls simulations can be computationally intensive. A study involving use of reduced FE models in attitude control simulations for the solar sail application has been undertaken. The method was implemented using the ANSYS [16] FE software and the MATLAB numerical analysis software package. The FE software is used to generate a structural system model in standard second-order matrix form. The system model is then reduced via Guyan reduction [17]. The reduced model is then imported to MATLAB. A representation of a control system is incorporated with the system model, and the model is converted to first order 
form, and simulated using built-in MATLAB numerical integration functions. The overall approach is similar to the approach outlined in Reference 18 for studying vibration control of turbomachinery blading.

The second order system FE model, including the control system and possible external disturbance loads, can be written as

$$
[M]\{\ddot{d}\}+[C]\{\dot{d}\}+[K]\{d\}=\left\{F_{e}\right\}+\left\{F_{c}\right\}
$$

where $\{d\}$ is a vector of nodal displacements, $\{\dot{d}\}$ is a vector of nodal velocities, $\{\ddot{d}\}$ is a vector of nodal accelerations, $\left\{F_{e}\right\}$ is a vector of external disturbance loads, and $\left\{F_{c}\right\}$ is a vector of control forces and moments. $[M],[C]$, and $[K]$ are the structural mass, damping, and stiffness matrices, respectively.

The model can be reduced via Guyan reduction to a set of $m$ master degrees of freedom (DOF), and written,

$$
\left[M_{r}\right]\left\{\ddot{d}_{m}\right\}+\left[C_{r}\right]\left\{\dot{d}_{m}\right\}+\left[K_{r}\right]\left\{d_{m}\right\}=\left\{F_{e-r}\right\}+\left\{F_{c-r}\right\}
$$

where $\left\{d_{m}\right\}$ is a $m \times 1$ vector of nodal displacements of the master DOF, $\left\{\dot{d}_{m}\right\}$ is a $m \times 1$ vector of nodal velocities of the master DOF, $\left\{\ddot{d}_{m}\right\}$ is $m \times 1$ vector of nodal accelerations of the master DOF, $\left\{F_{e-r}\right\}$ is a $m \times 1$ reduced vector of external disturbance loads, and $\left\{F_{c-r}\right\}$ is a $m \times 1$ vector of control forces and moments. Matrices $\left[\mathrm{M}_{\mathrm{r}}\right],\left[C_{r}\right]$, and $\left[K_{r}\right]$ are the reduced structural mass, damping, and stiffness matrices, respectively, each of size $m \times m$.

To convert the reduced model to state-space form, a vector of state variables, $\{\mathrm{q}\}$, is defined, where

$$
\{q\}=\left\{\begin{array}{l}
\left\{d_{m}\right\} \\
\left\{\dot{d}_{m}\right\}
\end{array}\right\}
$$

The following matrices are also defined:

$$
[R]=\left[\begin{array}{cc}
-[I] & {[Z]} \\
{[Z]} & {\left[M_{r}\right]}
\end{array}\right] \quad[H]=\left[\begin{array}{cc}
{[Z]} & {[I]} \\
{\left[K_{r}\right]} & {\left[C_{r}\right]}
\end{array}\right] \quad\left\{\bar{F}_{e-r}\right\}=\left\{\begin{array}{c}
\{Z\} \\
\left\{F_{e-r}\right\}
\end{array}\right\} \quad\left\{\bar{F}_{c-r}\right\}=\left\{\begin{array}{c}
\{Z\} \\
\left\{F_{c-r}\right\}
\end{array}\right\}
$$

where, for a model with $m$ retained master DOF, $[Z]$ is an $m \times m$ matrix of zeros, $[I]$ is an $m \times m$ identity matrix, and $\{Z\}$ is an $m \times 1$ column vector of zeroes. Using Equations 22, 23 and 24, the model can be written

$$
[R]\{\dot{q}\}+[H]\{q\}=\left\{\bar{F}_{e-r}\right\}+\left\{\bar{F}_{c-r}\right\}
$$

and then rearranged into standard state-space form as

$$
\{\dot{q}\}=[A]\{q\}+[B]\{u\}+\left\{P_{e}\right\}=-[R]^{-1}[H]\{q\}+[R]^{-1}\left\{\bar{F}_{c-r}\right\}+[R]^{-1}\left\{\bar{F}_{e-r}\right\}
$$

The vector, $\left\{P_{e}\right\}$, relates to external disturbance loads. In Equation 26, for the systems studied here, the coefficient matrix, $[A]$, is of size $2 m \times 2 m$. In general, for a multi-input system, $\{u\}$ is a vector of control inputs. In typical feedback control applications, the control input is proportional to measured system responses. It is assumed here that the control input, $\{u\}$, can be written as

$$
\{u\}=-[G]\{q\}
$$

where $[\mathrm{G}]$ is a matrix of control gains. Substituting Equation 27 into Equation 26 results in the closed-loop system equations,

$$
\{\dot{q}\}=[[A]-[B][G]]\{q\}+\left\{P_{e}\right\}
$$

or,

$$
\{\dot{q}\}=\left[A_{C L}\right]\{q\}+\left\{P_{e}\right\}
$$

The system response, $\{q(t)\}$, due to loads in the vector, $\left\{P_{e}\right\}$, and/or some initial conditions, $\{q(0)\}$, can then be calculated by standard numerical methods using this set of system equations. In this work, the built-in MATLAB function for performing Runge-Kutta integration is used. 


\section{Finite Element Simulations}

In an initial study, to gain preliminary verification of these FE modeling and simulation procedures for the solar sail application, a FE model was created corresponding as closely as possible to the two beam distributed parameter model described above. The model consists of twenty ANSYS 2D beam elements (ANSYS Beam3 elements), each with two end nodes and three DOF per node. The DOF at each node are translations, $U_{x}$ and $U_{y}$ and rotation, $\theta_{z}$.

Three lumped-mass/inertia elements (ANSYS Mass21 elements) are included at the hub and boom ends. The hub is constrained to zero translation. The reduced model retains as master DOF the rotation at the hub, $\theta_{z}$, and the translation, $U_{y}$, and rotation, $\theta_{z}$, at the boom ends. This example is a $10-\mathrm{m}$ demonstration solar sail. A schematic of the model and required modeling parameters are shown in Figure 28. For this simulation, an initial rigid body angular velocity is applied to the structure of $1.0 \mathrm{rad} / \mathrm{s}$ (counter-clockwise, according to Figure 28). In order to implement an initial rigid body rotation for the structure, initial angular velocities are imposed at the retained master $\theta_{z}$ DOF at the left end, right end, and hub. Also, corresponding initial translational velocities are imposed at the retained master $U_{y} \mathrm{DOF}$ at the left and right ends. So, for an initial rigid body angular velocity of $1 \mathrm{rad} / \mathrm{s}$ (counterclockwise), there is an initial translational y-direction velocity of $-7 \mathrm{~m} / \mathrm{s}$ at the left end, and $+7 \mathrm{~m} / \mathrm{s}$ at the right end. There is no disturbance torque assumed, and the control torque is defined as

$$
T_{c}=K_{a}\left(\theta(t)-\theta_{0}\right)+K_{b} \dot{\theta}(t) \text { where } K_{a}=-1000, K_{b}=-100 .
$$

Figures 29 and 30 present the results of these simulations. When the uncontrolled and controlled responses for the 2-D analytical model in Figure 29b) are compared to those of the reduced FE model in Figure 30b), a slightly different response is observed. The reduced model response is more lightly damped, and in particular, the trough following the initial peak is deeper and delayed in Figure 30b). This is not surprising as more modes participate in the reduced finite element model simulation than in the 2-D analytical model. However, the results from both models are in good agreement, which provides some verification for the finite element modeling procedures.

Additional simulations for the reduced FE modeling approach were conducted based on a model constructed to be of a size more typical of that expected for the integrated solar sail models. This model was derived from the highfidelity model used to generate Figure 1 and is described in References 8 and 9. The FE mesh is seen in Figure 31, where node 1 is at the hub, and nodes 2, 52,102, and 152 are at the tips. Details of the model are as follows:

- $\quad$ Four Booms: properties given in Table 2; ANSYS Pipe16 elements - 50 elements per boom.

- Control Mast: Length $=2 \mathrm{~m}$ (directed out of plane of sail from hub); 10 ANSYS Pipe 16 elements; radius $=$ $0.01705 \mathrm{~m}$; wall thickness $=0.005 \mathrm{~m}$; modulus of elasticity $=1.24 \times 10^{11} \mathrm{~N} / \mathrm{m}^{2} ;$ density $=7660 \mathrm{~kg} / \mathrm{m}^{3}$.

- Membrane: ANSYS Shell41 elements (connected along booms); shell thickness $=2.5 \times 10^{-6} \mathrm{~m}$; modulus of elasticity $=2.48 \times 10^{9} \mathrm{~N} / \mathrm{m}^{2} ;$ density $=1572.45 \mathrm{~kg} / \mathrm{m}^{3}$.

- Lumped Masses: Spacecraft - $228 \mathrm{~kg}$ at end of control mast; stowage - $54.84 \mathrm{~kg}$ at hub; tip masses at ends of booms $-0.58 \mathrm{~kg}$.

- 18 Retained Master DOF: At hub: $U_{x}, U_{y}, U_{z}, \theta_{x}, \theta_{y}, \theta_{z}$; at each of the four boom tips: $U_{x}, U_{y}, U_{z}$.

- Structural Damping: Proportional to the stiffness matrix, $[K]$, so that the damping matrix, $[C]$, is defined as $[C]=0.001 *[K]$.

- Control Moments: Applied at the hub, and based on feedback of hub angular displacements and angular velocities, according to: $M_{x}=-50,000 \theta_{x}-5,000 \dot{\theta}_{x}, M_{y}=-50,000 \theta_{y}-5,000 \dot{\theta}_{y}$.

$\mathrm{M}_{x}$ is a control moment at node 1 about the $\mathrm{x}$-direction, $\mathrm{M}_{y}$ is a control moment at node 1 about the $\mathrm{y}$ direction, $\theta_{x}$ and $\dot{\theta}_{x}$ are the angular displacement and velocity, respectively, about the x-direction at node 1 , and $\theta_{y}$ and $\dot{\theta}_{y}$ are the angular displacement and velocity, respectively, about the y-direction at node 1 .

In an initial simulation using this model, the excitation was a unit force applied for $0<t<1 s$ in the z-direction (out-of-plane) at two adjacent boom tips (nodes 2 and 52). The system response was simulated for the controlled and uncontrolled case. The results for rotation about the x-direction at the hub (node 1) are shown in Figure 32. In these results, linearly increasing rotation is seen in the uncontrolled response, with flexible solar sail motion seemingly superimposed on this underlying response. Hence, control designs should consider both rigid and flexible motion of the solar sails. 
A second simulation was run with the same model, but with a disturbance due to random out-of-plane forces. Disturbance force magnitudes ranged from 0 to $1 N$. Different forces were applied at each boom tip (nodes 2, 52, 102 , and 152) and the forces were updated every 0.001 seconds. The random input was implemented using the MATLAB "rand" command. Figure 33a) presents the uncontrolled and controlled results for angular displacement about the y-direction at the hub, and Figure 33b) presents the angular displacement about the x-direction at the hub. Simulations with three-dimensional solar radiation disturbance models integrated with the reduced finite element model are possible using this approach, but were considered beyond the scope of this effort.

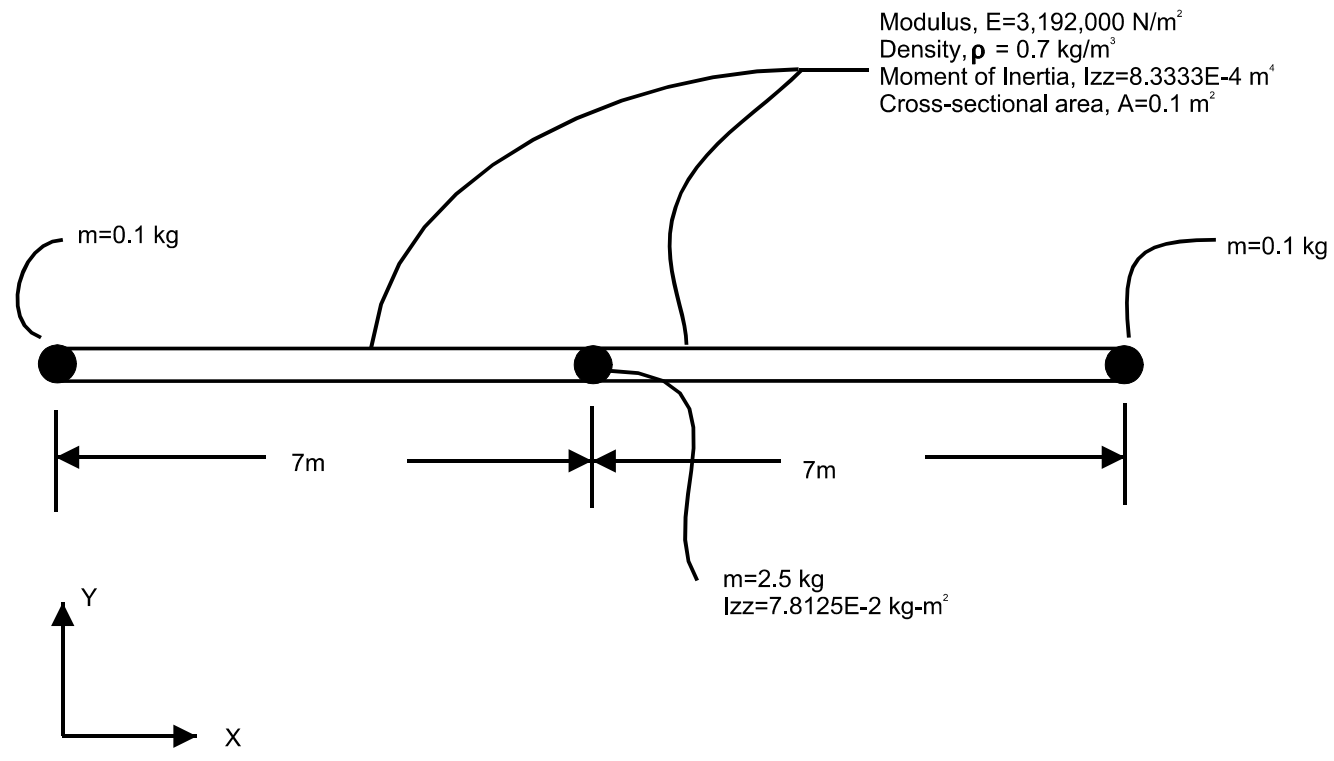

Figure 28. Finite-element model for verification of the reduced model approach.

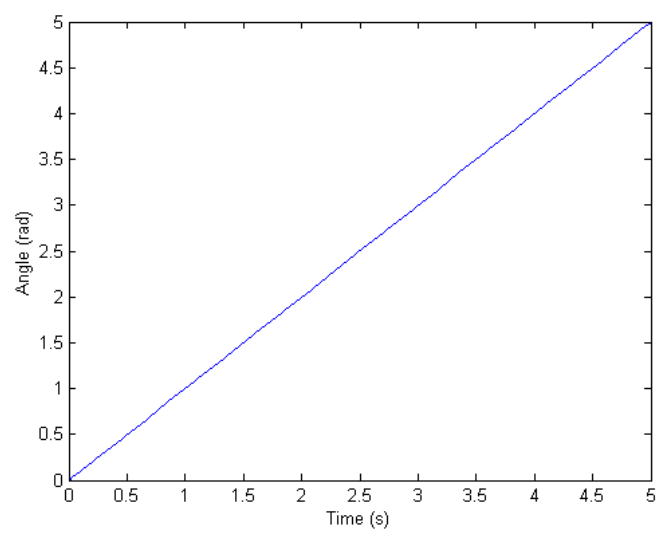

a) Uncontrolled angular response

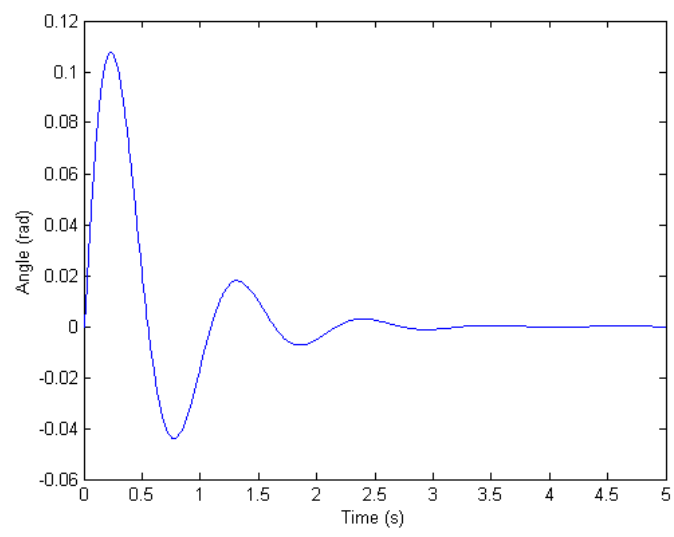

b) Controlled angular response

Figure 29. Analytical model results. 


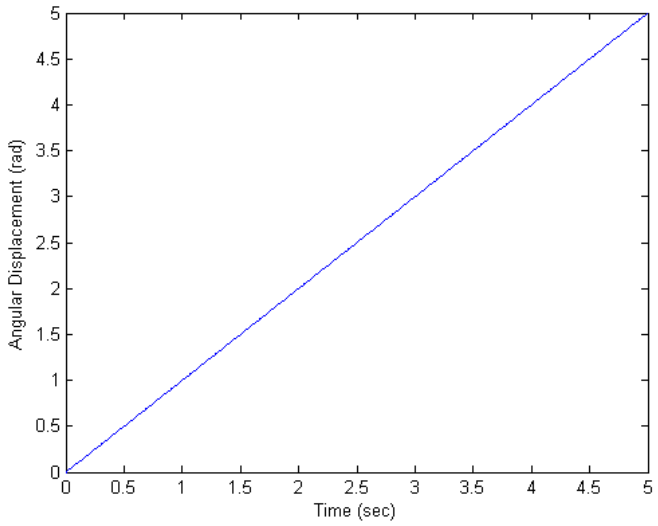

a) Uncontrolled angular response

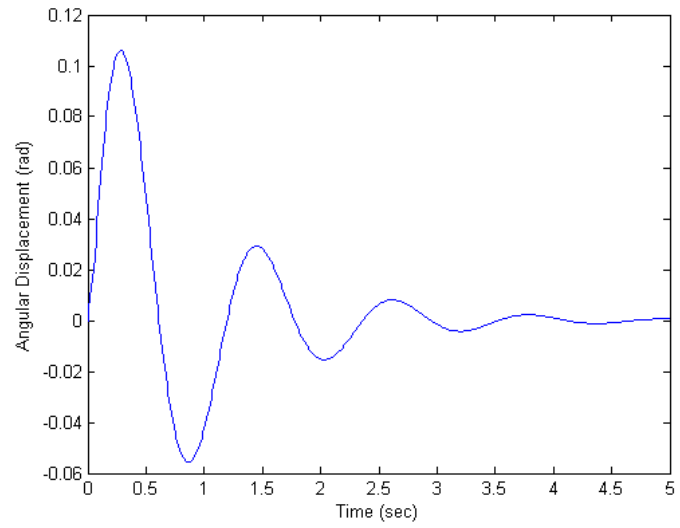

b) Controlled angular response

Figure 30. Reduced FE model results.

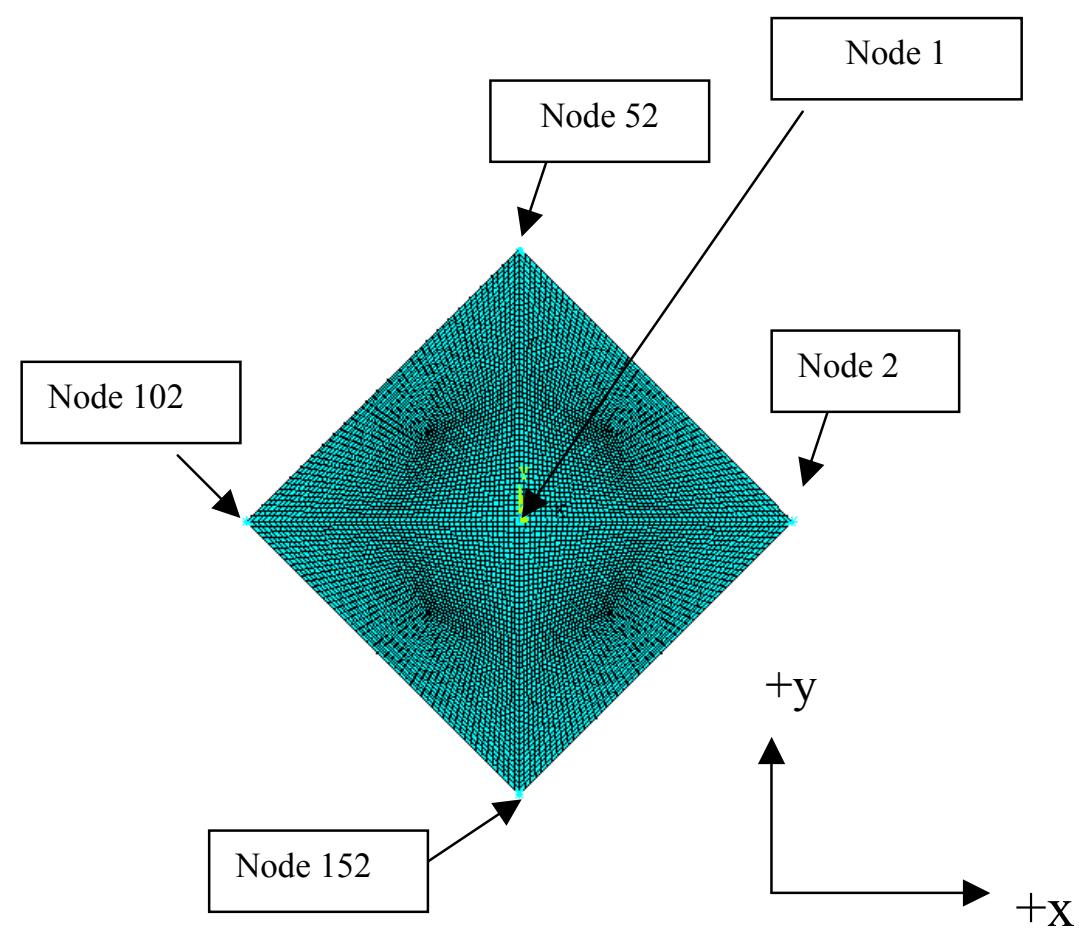

Figure 31. Representative finite-element model of a solar sail. 


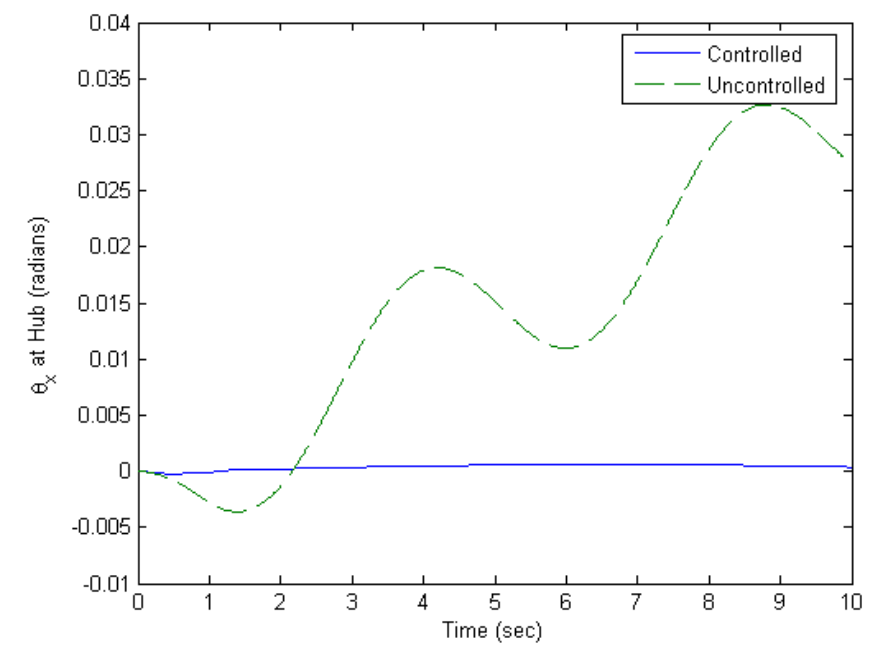

Figure 32. Simulation results with representative finite element solar sail model.

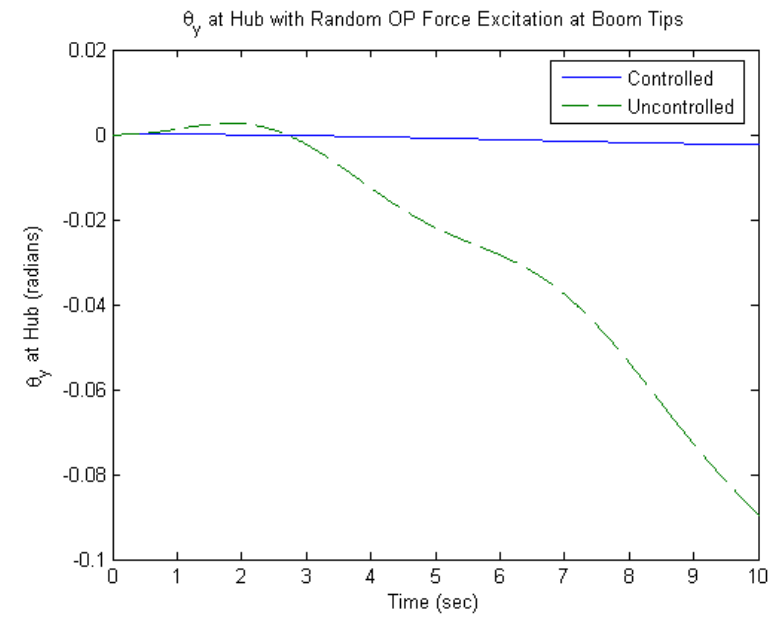

a) Angular response $\theta_{y}$

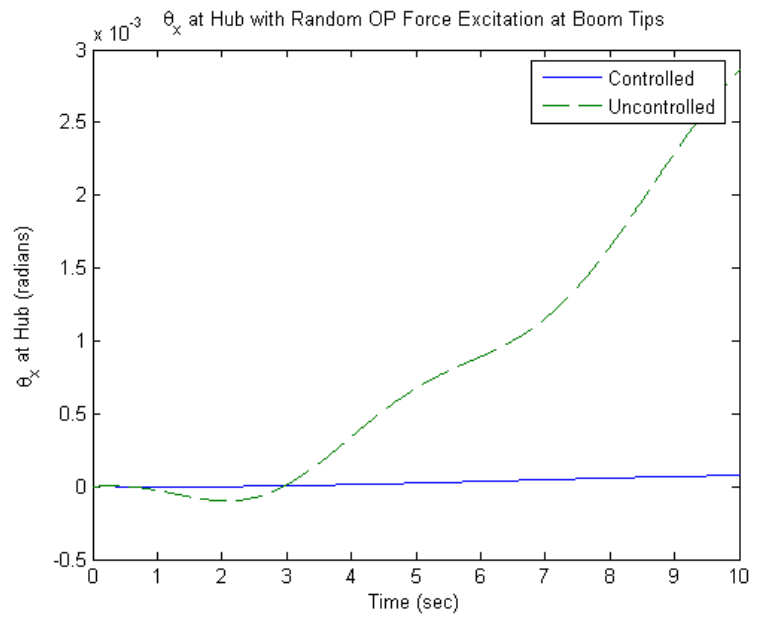

b) Angular response $\theta_{x}$

Figure33. Simulation results for a random force excitation at the boom tips with representative solar sail finite element model.

\section{Summary and Future Work}

In this paper, three models were developed for the response of flexible solar sails. The first model is a twodimensional idealization of a flexible solar sail representative of the class of solar sail systems in which the sail and booms move synchronously for the lower modes. The model consists of two flexible booms with a central hub and tip masses. Equations of motion were developed for the coupled vibrational response (reduced to the response of the first asymmetric mode only) and angular motion. Control simulations were run with linear feedback control of the vibrational response states and of the angular response states to reduce vibrational motion and to execute repositioning maneuvers. This model serves to develop physical understanding of the influence of flexibility. In addition, this model is used to validate planned closed-loop control simulation implementations with commercial finite element software. The second model is a two-dimensional solar radiation disturbance model to calculate the 
effect of solar sail shape on the resultant thrust, in-plane force and torque at the hub. The torque from this model was then input to the idealized model to demonstrate vibration and attitude control. A reduced finite element model also was developed and used to demonstrate vibration and attitude control of the solar sail. Limited verification of the response of the two-dimensional finite element model was provided by comparison to the response of the first analytical model developed herein. The finite element modeling approach was then extended to simulate both controlled and uncontrolled response of a full finite element model of a solar sail.

\section{Acknowledgments}

This effort was performed under a grant as part of NRA 02-OSS-01-IST2 Advanced Computational Methods for Solar Sails under the direction of Dr. John T. Wang of the Computational Structures and Materials Branch (CSMB), NASA Langley Research Center, Hampton, VA. The authors also gratefully acknowledge contributions of Mr. David. W. Sleight also of CSMB to this paper for his development of the high-fidelity finite element square solar sail model used as motivation.

The work described in this paper was funded in part by the In-Space Propulsion Technology Program, which is managed by NASA's Science Mission Directorate in Washington, D.C., and implemented by the In-Space Propulsion Technology Office at Marshall Space Flight Center in Huntsville, AL. The program objective is to develop in-space propulsion technologies that can enable or benefit near and mid-term NASA space science missions by significantly reducing cost, mass or travel times.

\section{References}

1. Garbe, G. and E.E. Montgomery, IV, “An Overview of NASA's Solar Sail Propulsion Project,” 39th AIAA/ASME/SAE/ASEE Joint Propulsion Conference and Exhibit, Huntsville, AL, July 2003.

2. Lichodziejewski, D., et al., "Bringing an Effective Solar Sail Design Toward TRL 6," AIAA 2003-4659, 39th AIAA/ASME/SAE/ASEE Joint Propulsion Conference and Exhibit, Huntsville, AL, July 2003.

3. Murphy, D.M., T.W. Murphey and P. Gierow, "Scalable Solar Sail Subsystem Design Considerations," AIAA 2002-1703, 43th AIAA/ASME/ASCE/AHS Structures, Structural Dynamics and Materials Conference, Denver, CO, April 2002.

4. Leifer, J., W. K. Belvin, J. T. Black and V. Behun, "Evaluation of Shear Compliant Borders for Wrinkle Reduction in Thin Film Membrane Structures," AIAA 2003-1984, 44 ${ }^{\text {th }}$ AIAA/ASME/ASCE/AHS Structures, Structural Dynamics and Materials Conference, Norfolk, VA, April 2003.

5. Wie, B., "Dynamic Modeling and Attitude Control of Solar Sail Spacecraft," JPL Contract No. 1228156 Final Report, January 10, 2002.

6. Wie, B., "Dynamic Modeling and Attitude Control of Solar Sail Spacecraft: Part I," AIAA-2002-4572, AIAA Guidance, Navigation, and Control Conference and Exhibit, Monterey, CA, Aug. 2002.

7. Wie, B., "Dynamic Modeling and Atittude Control of Solar Sail Spacecraft: Part II," AIAA-2002-4573, AIAA Guidance, Navigation, and Control Conference and Exhibit, Monterey, CA, Aug. 2002.

8. Sleight, D.W. and D.M. Muheim, "Parametric Studies of Square Solar Sails Using Finite Element Analysis," AIAA 2004-1709, 45th AIAA/ASME/ASCE/AHS Structures, Structural Dynamics and Materials Conference, Palm Springs, CA, April 2004.

9. Sleight, D.W. and D.M. Muheim, "Parametric Studies of Square Solar Sails,” NASA TM in preparation.

10. Junkins, J.L. and Y. Kim, Introduction to Dynamics and Control of Flexible Structures, J.S. Przemieniecki, Editor, American Institute of Aeronautics and Astronautics, Inc., Washington, DC, 1993.

11. Mei, K., "Analytical Models for the Nonlinear Response of a Flexible Solar Array," Masters Thesis, University of Kentucky, Lexington, KY, August 1997. 
12. Mei, K., "Nonlinear Vibration of Beam Structures: Analytical and Explicit Dynamics FEA Evaluations," PhD Dissertation, University of Kentucky, Lexington, KY, May 2000.

13. Murphy, D.M. and B.D. Macy, "Demonstration of a 10-m Solar Sail System", AIAA-2004-1576, 45th AIAA/ASME/ASCE/AHS Structures, Structural Dynamics and Materials Conference, Palm Springs, CA, April 2004.

14. Murphey, T.W., D.M. Murphy, M.M. Mikulas, Jr. and A.L. Adler, "A Method to Quantify the Thrust Degradation Effects of Structural Wrinkles in Solar Sails," AIAA 2002-1560, 43rd AIAA/ASME/ASCE/AHS Structures, Structural Dynamics and Materials Conference, Denver, CO, April 2002.

15. MATLAB, Version 6.1.0.450, Release 12.1, Copyright 1984-2001, The Mathworks, Inc.

16. ANSYS, Release 7.1, Copyright 2003, ANSYS, Inc.

17. Guyan, R.J., "Reduction of Stiffness and Mass Matrices,” AIAA Journal, Vol. 3, No. 2, 1965.

18. Angelucci, R.J., J.R. Baker and V.R. Capece, "A Study on Active Vibration Control for Stator Vanes in a Research Compressor," AIAA-2004-3752, 40th AIAA/ASME/SAE/ASEE Joint Propulsion Conference, Ft. Lauderdale, FL, 2004. 